\title{
Molecular Engineering of High-Performance Aggregation-Induced Emission Photosensitizers to Boost Cancer Theranostics Mediated by Acid-Triggered Nucleus-Targeted Nanovectors
}

Zhijun Zhang, ${ }_{,+,, \square}$ Wenhan Xu, ${ }^{\oint, \square}$ Peihong Xiao, ${ }^{\dagger, \ddagger}$ Miaomiao Kang, ${ }^{\dagger, \ddagger}$ Dingyuan Yan,,$^{\dagger, \neq}$ Haifei Wen, ${ }^{\dagger}$ Nan Song, ${ }^{\dagger, \ddagger}$ Dong Wang, ${ }^{* \dagger}+$ and Ben Zhong Tang*,\&

\section{Table of Contents}

\section{Methods}

\section{Synthesis and Characterization}

Figure S1. The synthetic routes to AIEgens.

Figure S2. ${ }^{1} \mathrm{H}$ NMR spectrum of $\mathbf{2 a}$.

Figure S3. ${ }^{13} \mathrm{C}$ NMR spectrum of $2 \mathbf{a}$.

Figure S4. ${ }^{1} \mathrm{H}$ NMR spectrum of $\mathbf{2} \mathbf{b}$.

Figure S5. ${ }^{13} \mathrm{C}$ NMR spectrum of $\mathbf{2 b}$.

Figure S6. HRMS spectrum of $\mathbf{2} \mathbf{b}$.

Figure S7. ${ }^{1} \mathrm{H}$ NMR spectrum of $2 \mathrm{c}$.

Figure S8. ${ }^{13} \mathrm{C}$ NMR spectrum of 2c.

S13

Figure S9. HRMS spectrum of 2c.

S13

Figure S10. ${ }^{1} \mathrm{H}$ NMR spectrum of $\mathbf{3 a}$.

Figure S11. HRMS spectrum of $\mathbf{3 a}$.

S14

Figure S12. ${ }^{1} \mathrm{H}$ NMR spectrum of $\mathbf{3 b}$.

S15

Figure S13. ${ }^{13} \mathrm{C}$ NMR spectrum of $\mathbf{3 b} . \quad \mathrm{S} 15$

Figure S14. HRMS spectrum of $\mathbf{3 b} . \quad$ S16

Figure S15. ${ }^{1} \mathrm{H}$ NMR spectrum of 3c. $\quad$ S16

$\begin{array}{lr}\text { Figure S16. }{ }^{13} \mathrm{C} \text { NMR spectrum of 3c. } & \text { S17 }\end{array}$

$\begin{array}{ll}\text { Figure S17. HRMS spectrum of 3c. } & \text { S17 }\end{array}$

Figure S18. ${ }^{1} \mathrm{H}$ NMR spectrum of 4 a. $\quad$ S18

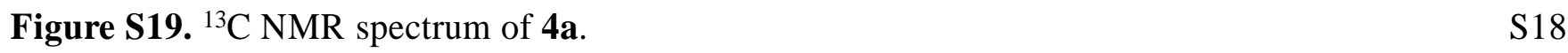

$\begin{array}{lr}\text { Figure S20. HRMS spectrum of 4a. } & \text { S19 }\end{array}$

Figure S21. ${ }^{1} \mathrm{H}$ NMR spectrum of $\mathbf{4 b} . \quad S 19$

Figure S22. ${ }^{13} \mathrm{C}$ NMR spectrum of $\mathbf{4 b}$. $\quad$ S20

Figure S23. HRMS spectrum of $\mathbf{4 b}$. $\quad$ S20

Figure S24. ${ }^{1} \mathrm{H}$ NMR spectrum of $\mathbf{4 c}$. $\quad$ S21

Figure S25. ${ }^{13} \mathrm{C}$ NMR spectrum of 4c. $\quad$ S21

$\begin{array}{ll}\text { Figure S26. HRMS spectrum of } 4 c . & \text { S22 }\end{array}$ 
Figure S27. ${ }^{1} \mathrm{H}$ NMR spectrum of TPE-TTMN. $\quad$ S22

Figure S28. ${ }^{13} \mathrm{C}$ NMR spectrum of TPE-TTMN. $\quad$ S23

Figure S29. HRMS spectrum of TPE-TTMN. $\quad$ S23

Figure S30. ${ }^{1} \mathrm{H}$ NMR spectrum of TPE-TTMN-OMe. $r$

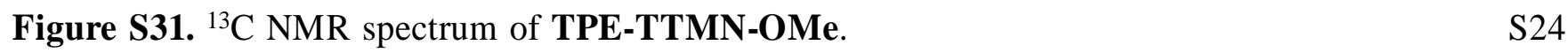

Figure S32. HRMS spectrum of TPE-TTMN-OMe. $\quad$ S25

Figure S33. ${ }^{1} \mathrm{H}$ NMR spectrum of TPE-TTMN-TPA. $\quad$ S25

Figure S34. ${ }^{13} \mathrm{C}$ NMR spectrum of TPE-TTMN-TPA. $\quad$ S26

Figure S35. HRMS spectrum of TPE-TTMN-TPA. $\quad$ S26

Figure S36. ${ }^{1} \mathrm{H}$ NMR spectrum of PLA12K-PEG5K-TAT-SA and intermediates. $\quad$ S27

$\begin{array}{lr}\text { Figure S37. Absorption spectra and molar absorptivity. } & \text { S28 }\end{array}$

$\begin{array}{lr}\text { Table S1. Optical properties of AIEgens. } & \text { S28 }\end{array}$

$\begin{array}{lr}\text { Figure S38. AIE property measurements. } & \text { S28 }\end{array}$

Figure S39. Calculated HOMOs and LUMOs of AIEgens. $\quad$ S29

$\begin{array}{lr}\text { Figure S40. Singlet oxygen generation measurement. } & \text { S29 }\end{array}$

Figure S41. Hydroxyl radical generation measurement. $\quad$ S30

$\begin{array}{lr}\text { Figure S42. Superoxide generation measurement. } & \text { S30 }\end{array}$

$\begin{array}{lr}\text { Figure S43. Storage stability analysis. } & \text { S30 }\end{array}$

$\begin{array}{lr}\text { Figure S44. Quantitative cellular uptake efficiency. } & \text { S31 }\end{array}$

$\begin{array}{lr}\text { Figure S45. Photostability test. } & \text { S31 }\end{array}$

Figure S46. Quantitative fluorescence intensity of DCFH inside cells. $\quad$ S32

Figure S47. Ex vivo NIR fluorescence images of tumor and major organs. $\quad$ S32

Figure S48. Survival curves of 4T1 tumor-bearing mice with different treatments. S32

Table S2. Routine blood parameters of mice. $\quad S 33$

$\begin{array}{ll}\text { References } & \text { S33 }\end{array}$ 


\section{Methods}

\section{Detection of ROS generation in aqueous solution}

The commonly used DCFH-DA was used as an indicator to investigate the ROS generation efficiency of AIEgens in aqueous solution. The pre-activated DCFH-DA solution (DCFH, $40 \mu \mathrm{M}$ ) was added into the sample solution containing AIEgens $(0.2 \mu \mathrm{M})$ of TTMN, TPE-TTMN, TPE-TTMN-OMe or TPE-TTMN-TPA. Afterward, the mixed solutions were irradiated by white light $\left(22.1 \mathrm{~mW} \mathrm{~cm}^{-2}\right)$ for different time intervals. The fluorescence of indicator at $525 \mathrm{~nm}$ triggered by AIEgen-sensitized ROS was measured at the excitation of $488 \mathrm{~nm}$.

\section{Preparation of T4-NPs}

$1 \mathrm{mg}$ of compound TPE-TTMN-TPA (T4) and $20 \mathrm{mg}$ of amphiphilic copolymers (15 mol\% PLA-PEG-TAT-SA and 85 mol\% PLA-PEG) were firstly dissolved in $1 \mathrm{~mL}$ of THF and then poured into $9 \mathrm{~mL}$ of deionized water. After that, the mixture was sonicated for 2 min continuously by a microtip probe sonicator (XL2000, Misonix Incorporated, NY) (45\% output power), which was further transferred into dialysis tube (MWCO $3500 \mathrm{Da}$ ) and dialyzed against deionized water for 24 h with renewal every $4 \mathrm{~h}$. The final obtained solution of T4-loaded nanoparticles (T4-NPs) was freeze-dried or concentrated by ultrafiltration before utilization. Based on a pre-established calibration absorption curve, the loading content (DLC) and entrapment efficiency (EE) of T4 were determined to be $4.46 \mathrm{wt} \%$ and $93.2 \%$, respectively.

\section{Particle size and morphology}

The size distribution of T4-NPs was detected by DLS at the concentration of $100 \mu \mathrm{g} \mathrm{mL}^{-1}$ in aqueous solution, and the morphology of T4-NPs was observed using TEM with a concentration of $1 \mathrm{mg}$ $\mathrm{mL}^{-1}$.

\section{Storage stability}

The concentrated aqueous solution of T4-NPs $\left(10 \mathrm{mg} \mathrm{mL}^{-1}\right)$ was diluted with PBS or PBS $+10 \%$ FBS into $100 \mu \mathrm{g} \mathrm{mL}-1$. At designated time, aliquot of the solution was taken and monitored by DLS and UV-vis spectrophotometer.

\section{Acid-responsive behavior study}

The concentrated aqueous solution of T4-NPs $\left(10 \mathrm{mg} \mathrm{mL}^{-1}\right)$ was diluted with different biomimetic buffer solutions including $\mathrm{pH} 7.4$ and $\mathrm{pH} 5.0 \mathrm{PBS}$ into $100 \mu \mathrm{g} \mathrm{mL}-1$, respectively. After $24 \mathrm{~h}$ incubation at $37^{\circ} \mathrm{C}$, the samples were measured by DLS to investigate the zeta potential variations. 


\section{Cell culture}

Mouse breast cancer 4T1 cell line was purchased from Chinese Academy of Science Cell Bank for Type Culture Collection, and cultured in 1640 culture medium containing 10\% FBS and 1\% antibiotics (penicillin-streptomycin) at $37{ }^{\circ} \mathrm{C}$ in a humidified environment of $5 \% \mathrm{CO}_{2}$.

\section{Photostability test}

To quantitatively investigate the photobleaching resistance of T4-NPs, we continuously scanned the T4-NPs-labelled 4T1 cells with $543 \mathrm{~nm}$ laser excitation (2\% laser intensity), and recorded the corresponding fluorescence signal at each scan. Conditions: for T4-NPs, excitation wavelength: 543 $\mathrm{nm}$ and emission filter: 650-750 nm; for LTG, excitation wavelength: $488 \mathrm{~nm}$ and emission filter: 500-550 nm.

\section{Cell viability test}

After being seeded in a 96-well plate at a density of $5 \times 10^{3}$ cells per well and further cultured for 24 h, 4T1 cells were incubated with different concentrations of T4-NPs. After 24 h incubation, the cells were exposed to white light irradiation $\left(24 \mathrm{~mW} \mathrm{~cm}^{-2}\right)$ for $20 \mathrm{~min}$. Meanwhile, the dark cytotoxicity study was conducted on the T4-NPs incubated cells without light irradiation. After incubation for another $24 \mathrm{~h}$, the cells were washed with PBS and further incubated in fresh serum-free media containing 10\% CCK-8 for $2 \mathrm{~h}$ in the dark. Subsequently, the absorbance at $450 \mathrm{~nm}$ was measured on a microplate reader.

\section{Live-dead cell staining}

After being cultured in a glass bottom dish, 4T1 cells were treated with T4-NPs $\left(20 \mu \mathrm{g} \mathrm{mL}^{-1} \mathrm{~T} 4\right)$ for $24 \mathrm{~h}$, followed by white light irradiation $\left(24 \mathrm{~mW} \mathrm{~cm}^{-2}\right)$ for $20 \mathrm{~min}$. After further incubation for another $24 \mathrm{~h}$ at $37^{\circ} \mathrm{C}$, the cells were successively stained with PI $\left(60 \mu \mathrm{g} \mathrm{mL} \mathrm{L}^{-1}\right)$ and FDA $(100 \mu \mathrm{g}$ $\mathrm{mL}^{-1}$ ) for $10 \mathrm{~min}$, respectively. Last, the cells were gently washed and then imaged by CLSM. Conditions: excitation wavelength: $488 \mathrm{~nm}$ for FDA and $543 \mathrm{~nm}$ for PI; emission filter: 500-550 nm for FDA and 550-650 nm for PI.

\section{Intracellular ROS generation}

4T1 cells seeded in a glass bottom dish were cultured for $24 \mathrm{~h}$ and then treated with T4-NPs $(20 \mu \mathrm{g}$ $\left.\mathrm{mL}^{-1} \mathrm{~T} 4\right)$ for $24 \mathrm{~h}$. Then the ROS indicator DCFH-DA $(10 \mu \mathrm{M})$ was introduced to incubate with the T4-NPs loaded cells for $20 \mathrm{~min}$. Subsequently, the cells were exposed to white light irradiation (24 $\mathrm{mW} \mathrm{cm}{ }^{-2}$ ) for 20 min after washing with PBS, and then imaged by CLSM. Conditions: $488 \mathrm{~nm}$ for excitation wavelength and 500-550 nm for emission filter. 


\section{Animals and tumor model}

All animals operations complied with the protocols approved by the Administrative Committee on Animal Research in Shenzhen Graduate School, Peking University. The xenograft tumor models were established by subcutaneous injection of $4 \mathrm{~T} 1$ cells $\left(5 \times 10^{5}\right)$ in PBS buffer into the right flanks of BALB/c nude mice ( about 4 weeks old).

\section{In vivo NIR fluorescent imaging}

The 4T1 tumor-bearing mice were firstly intravenously administered with T4-NPs (10 mg T4 per kg mouse). Then, the mice were anesthetized and imaged by IVIS Spectrum imaging system (PerkinElmer) at 1, 3, 6, 12 and $24 \mathrm{~h}$ after injection. After that, the mice were subsequently sacrificed. Major organs (heart, liver, spleen, lung and kidney) and tumor were collected for NIR fluorescent imaging and quantitative analyses using IVIS Spectrum imaging system.

\section{In vivo phototherapeutic study}

20 tumor-bearing mice were randomly divided into 4 groups and treated with (1) Saline, (2) Saline+L, (3) T4-NPs and (4) T4-NPs+L, respectively. For group (1) and (3), $200 \mu \mathrm{L}$ of saline and T4-NPs (10 mg T4 kg-1) were separately intravenously injected into the 4T1 tumor-bearing mice. In terms of group (2) and (4), white light irradiation was applied for $20 \mathrm{~min}$ at $12 \mathrm{~h}$ after injection of saline and T4-NPs (10 mg T4 kg-1), respectively.Typical treatments were performed every 3 days for 15 days. After a variety of treatments, the mouse body weight and tumor volume were recorded using a balance and vernier caliper every 3 days. The tumor volume was determined according to the recorded size of tumor. Relative tumor volume was calculated as $\mathrm{RTV}=\mathrm{V} / \mathrm{V}_{0}\left(\mathrm{~V}_{0}\right.$ was the initial tumor volume).

\section{Histological and immunohistochemical analyses}

After complete treatment of 15 days, all the mice were humanely sacrificed, followed by the excision and weigh of tumors, which were then fixed in $4 \%$ paraformaldehyde, embedded in paraffin, and sliced at $5 \mu \mathrm{m}$ thickness. Afterward, the paraffin sections were administrated with H\&E staining and immunohistochemical staining for TUNEL, CD31, and Ki-67 measurements. The stained slices were lastly imaged by an inverted optical microscopy.

\section{In vivo biosafety evaluation}

Healthy BALB/c mice (4 5 weeks old) were admistrated with T4-NPs (10 mg T4 per kg mouse) by intravenously injection. After one week, the blood samples of the mice were collected from optic vein for hematological and serum biochemical analyses. Meanwhile, the major organs (heart, liver, 
spleen, lung and kidney) were also dissected from the mice for further H\&E analysis after being sacrificed.

\section{Synthesis and Characterization}

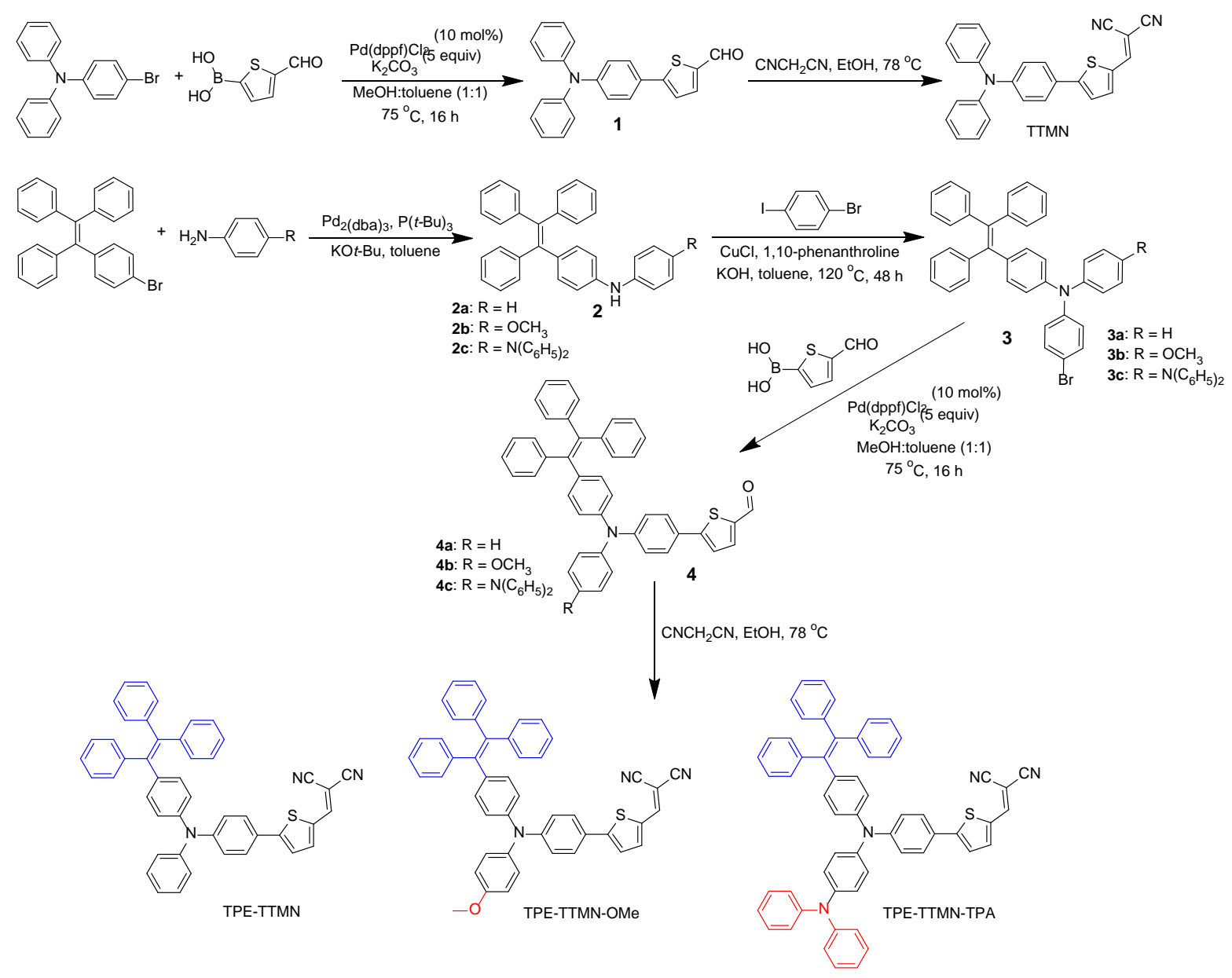

Figure S1. Synthetic routes to the AIEgens.

Synthesis of TTMN

TTMN was synthesized according to the literature method. ${ }^{1}$

General procedure for synthesis of compound 2

A solution of 1-(4-Bromophenyl)-1,2,2-triphenylethylene (2.05 g, $5 \mathrm{mmol})$, substituted aniline (6.5 mmol), tri-tert-butylphosphine (16.2 mg, $0.08 \mathrm{mmol}), \mathrm{Pd}_{2}(\mathrm{dba}) 3(64 \mathrm{mg}, 0.07 \mathrm{mmol})$ and sodium tert-butoxide (625 mg, $6.5 \mathrm{mmol}$ ) was refluxed under nitrogen in dry toluene $(30 \mathrm{~mL})$ at $110{ }^{\circ} \mathrm{C}$ for $24 \mathrm{~h}$. After cooling to room temperature, the solvent was removed by evaporation under reduced pressure. Water $(30 \mathrm{~mL})$ and chloroform $(200 \mathrm{~mL})$ were then added. The organic layer was separated and washed with brine, dried over anhydrous $\mathrm{MgSO}_{4}$ and evaporated to dryness under reduced 
pressure. The crude product was purified by column chromatography on silica gel using hexane/chloroform (v/v = 5/1) as eluent to afford compound 2.

\section{General procedure for synthesis of compound 3}

Compound 2 (8.9 mmol), 4-bromoiodobenzene (2.97 g, $10.6 \mathrm{mmol})$ and 1,10-phenanthroline (0.27 g, $1.5 \mathrm{mmol})$ were dissolved in toluene $(30 \mathrm{~mL})$. After the solution was heated to $100{ }^{\circ} \mathrm{C}, \mathrm{CuCl}(0.15 \mathrm{~g}$, $1.5 \mathrm{mmol}$ ) and $\mathrm{KOH}$ (1.23 g, $22.0 \mathrm{mmol})$ were added under $\mathrm{N}_{2}$ purge. The mixture was refluxed for $48 \mathrm{~h}$ at $120{ }^{\circ} \mathrm{C}$. After being cooled, the mixture was washed with $\mathrm{H}_{2} \mathrm{O}(50 \mathrm{~mL})$ three times and the organic phase was dried over $\mathrm{Na}_{2} \mathrm{SO}_{4}$. After removal of the solvent, the residual was purified on a silica gel column with ethyl acetate/petroleum (v/v = 1/40) as eluent, giving compound 3.

\section{General procedure for synthesis of compound 4}

A mixture of compound 3 (1.0 eq), (5-formylthiophen-2-yl)boronic acid (2.0 eq), $\mathrm{Pd}(\mathrm{dppf}) \mathrm{Cl}_{2}$ (10 mol\%) and $\mathrm{K}_{2} \mathrm{CO}_{3}(5.0$ eq) were added in mixed solvent $(\mathrm{MeOH} /$ toluene, $\mathrm{v} / \mathrm{v}=1 / 1)$. The reaction mixture was heated to $75{ }^{\circ} \mathrm{C}$ for $16 \mathrm{~h}$. After $16 \mathrm{~h}$, the reaction mixture was filtered and the solvent was removed. The residue was dissolved in DCM and washed by water. The combined organic layer was dried by $\mathrm{MgSO}_{4}$ anhydrous and then filtered. Solvent was removed and the residue was purified by silica gel chromatography, giving compound 4 .

General procedure for syntheses of AIEgens TPE-TTMN, TPE-TTMN-OMe, and TPE-TTMN-TPA The mixture of compound 4 (1.0 eq) and malononitrile (2.0 eq) in dry EtOH was refluxed for $72 \mathrm{~h}$ at $78{ }^{\circ} \mathrm{C}$. After being cooled, the solvent was removed, and the residual was purified on a silica gel column with dichloromethane/petroleum $(\mathrm{v} / \mathrm{v}=1 / 20)$ as eluent, pure AIEgens were obtained.

Spectral data of the compounds

TTMN: ${ }^{1} \mathrm{H}$ NMR (400 MHz, $\left.\mathrm{CDCl}_{3}\right): 7.96$ (d, $\left.J=8.4 \mathrm{~Hz}, 2 \mathrm{H}\right), 7.73$ (t, $\left.J=6.6 \mathrm{~Hz}, 3 \mathrm{H}\right), 7.52(\mathrm{~d}, J=$ 8.8Hz, 2H), 7.28-7.32 (m, 4H), 7.07-7.16 (m, 8H). ESI HRMS: calcd. for $\mathrm{C}_{28} \mathrm{H}_{19} \mathrm{~N}_{3}[\mathrm{M}]^{+}$: 397.1579, found: 397.1557.

2a was isolated as green solid with $82 \%$ yield. ${ }^{1} \mathrm{H}$ NMR $\left(400 \mathrm{MHz}, \mathrm{C}_{4} \mathrm{D}_{8} \mathrm{O}\right): 7.30(\mathrm{~s}, 1 \mathrm{H}), 7.16$ (t, $J=$ $7.4 \mathrm{~Hz}, 4 \mathrm{H}), 6.94-7.09$ (m, 23H), 6.89 (t, $J=6.6 \mathrm{~Hz}, 2 \mathrm{H}), 6.76-6.84$ (m, 4H). ${ }^{13} \mathrm{C}$ NMR (100 MHz, $\left.\mathrm{C}_{4} \mathrm{D}{ }_{8} \mathrm{O}\right):$ 149.40, 145.57, 145.41, 145.35, 143.89, 142.21, 141.62, 140.74, 140.58, 135.91, 133.34, 132.53, 132.44, 132.40, 129.98, 128.63, 128.51, 127.72, 127.24, 127.11, 127.04, 123.96, 122.76, 119.87, 116.35 .

2b was isolated as green solid with 85\% yield. ${ }^{1} \mathrm{H}$ NMR (400 $\left.\mathrm{MHz}, \mathrm{CDCl}_{3}\right)$ : 7.02-7.15 (m, 17H), 
6.83-6.88 (m, 4H), 6.65 (t, $J=4.2 \mathrm{~Hz}, 2 \mathrm{H}), 5.45$ (s, 1H), 3.79 (s, 3H). $\left.{ }^{13} \mathrm{C} \mathrm{NMR} \mathrm{(100} \mathrm{MHz,} \mathrm{CDCl}_{3}\right)$ : 155.16, 144.28, 144.16, 144.10, 143.35, 140.82, 139.47, 135.42, 134.83, 132.44, 131.46, 131.39, 131.35, 127.68, 127.53, 126.26, 126.12, 126.07, 122.0, 114.58, 114.44, 55.54. ESI HRMS: calcd. for $\mathrm{C}_{33} \mathrm{H}_{27} \mathrm{NO}[\mathrm{M}]^{+}:$453.2093, found: 453.2081.

2c was isolated as green solid with $77 \%$ yield. ${ }^{1} \mathrm{H}$ NMR (400 MHz, $\left.{ }_{4}{ }_{8} 8 \mathrm{O}\right): 7.30$ (s, 1H), 7.16 (d, $J$ $=7.4 \mathrm{~Hz}, 4 \mathrm{H}), 6.94-7.09$ (m, 23H), 6.89 (t, $J=6.6 \mathrm{~Hz}, 2 \mathrm{H}), 6.83$ (d, $J=8.0 \mathrm{~Hz}, 2 \mathrm{H}), 6.77$ (d, $J=7.6$ $\mathrm{Hz}, 2 \mathrm{H}) .{ }^{13} \mathrm{C}$ NMR (100 MHz, $\left.\mathrm{C}_{4} \mathrm{D} 8 \mathrm{O}\right): 149.40,145.57,145.41,145.35,143.89,142.21,141.62$, 140.74, 140.58, 135.91, 133.34, 132.53, 132.44, 132.40, 129.98, 128.63, 128.51, 127.72, 127.24, 127.11, 127.04, 123.96, 122.76, 119.87, 116.35. ESI HRMS: calcd. for $\mathrm{C}_{44} \mathrm{H}_{34} \mathrm{~N}_{2}[\mathrm{M}]^{+}:$590.2722, found: 590.2725 .

3a was isolated as green solid with $42 \%$ yield. ${ }^{1} \mathrm{H}$ NMR (400 MHz, $\mathrm{CD}_{2} \mathrm{Cl}_{2}$ ): 7.31 (d, $J=8.4 \mathrm{~Hz}$, 2H), $7.25(\mathrm{t}, J=7.8 \mathrm{~Hz}, 2 \mathrm{H}), 7.04-7.15(\mathrm{~m}, 18 \mathrm{H}), 6.78-6.91(\mathrm{~m}, 6 \mathrm{H})$. ESI HRMS: calcd. for $\mathrm{C}_{38} \mathrm{H}_{28} \mathrm{BrN}[\mathrm{M}]^{+}: 577.1405$, found: 577.1424.

3b was isolated as green solid with 49\% yield. ${ }^{1} \mathrm{H}$ NMR (400 $\left.\mathrm{MHz}, \mathrm{CDCl}_{3}\right)$ : 6.99-7.13 (m, 19H), 6.81-6.85 (m, 6H), 6.74 (d, $J=8.0 \mathrm{~Hz}, 2 \mathrm{H}), 3.80$ (s, 3H). ${ }^{13} \mathrm{C}$ NMR (100 MHz, CDCl $): 156.36$, 147.06, 145.70, 144.02, 143.74, 143.54, 140.58, 140.48, 139.97, 137.73, 132.16, 131.87, 131.34, 127.61, 127.58, 127.26, 126.41, 126.32, 126.28, 123.98, 121.89, 114.77, 113.77, 55.46. ESI HRMS: calcd. for $\mathrm{C}_{39} \mathrm{H}_{30} \mathrm{BrNO}[\mathrm{M}]^{+}$: 607.1511, found: 607.1492.

3c was isolated as green solid with $46 \%$ yield. ${ }^{1} \mathrm{H}$ NMR (400 $\mathrm{MHz}, \mathrm{CD}_{2} \mathrm{Cl}_{2}$ ): 7.25-7.32 (m, 6H), 6.82-7.12 (m, 31H). ${ }^{13} \mathrm{C}$ NMR (100 MHz, $\left.\mathrm{CD}_{2} \mathrm{Cl}_{2}\right)$ : 144.53, 144.37, 144.17, 142.47, 141.24, 132.49, 131.80, 129.75, 128.18, 128.16, 126.97, 126.91, 126.87, 126.42, 125.79, 124.39, 123.14. ESI HRMS: calcd. for $\mathrm{C}_{50} \mathrm{H}_{37} \mathrm{BrN}_{2}[\mathrm{M}]^{+}$: 744.2140, found: 744.2134 .

4a was isolated as yellow solid with 83\% yield. ${ }^{1} \mathrm{H}$ NMR (400 MHz, $\mathrm{CD}_{2} \mathrm{Cl}_{2}$ ): 9.84 (s, 1H), 7.72 (d, $J$ $=4.0 \mathrm{~Hz}, 1 \mathrm{H}), 7.54$ (d, $J=8.8 \mathrm{~Hz}, 2 \mathrm{H}), 7.28-7.34$ (m, 3H), 7.00-7.18 (m, 20H), 6.95 (d, $J=8.4 \mathrm{~Hz}$, 2H), 6.85 (d, $J=8.4 \mathrm{~Hz}, 2 \mathrm{H}) .{ }^{13} \mathrm{C}$ NMR (100 MHz, $\left.\mathrm{CD}_{2} \mathrm{Cl}_{2}\right):$ 183.05, 154.65, 149.44, 147.33, 145.73, 144.47, 144.27, 144.05, 141.97, 141.53, 141.11, 139.87, 138.35, 132.82, 131.82, 131.78, 131.75, 129.96, 128.21, 128.18, 128.15, 127.68, 127.02, 126.97, 126.92, 126.69, 125.68, 124.52, 124.42, 123.55, 122.91. ESI HRMS: calcd. for $\mathrm{C}_{43} \mathrm{H}_{31} \mathrm{NOS}[\mathrm{M}]^{+}: 609.2126$, found: 609.2106.

4b was isolated as yellow solid with $80 \%$ yield. ${ }^{1} \mathrm{H}$ NMR (400 MHz, $\mathrm{C}_{4} \mathrm{D}_{8} \mathrm{O}$ ): 9.81 (s, $\left.1 \mathrm{H}\right), 7.77$ (s, 1H), 7.55 (d, $J=8.4 \mathrm{~Hz}, 2 \mathrm{H}), 7.40$ (s, $1 \mathrm{H}), 7.01-7.12$ (m, 17H), 6.80-6.96 (m, 8H), 3.77 (s, 3H). ${ }^{13} \mathrm{C}$ NMR (100 MHz, C4 $\left.{ }_{8} \mathrm{O}\right):$ 182.77, 158.35, 154.57, 150.24, 146.71, 145.20, 144.89, 144.69, 142.96, 
141.99, 141.80, 140.59, 139.63, 138.55, 133.30, 132.40, 132.35, 128.77, 128.67, 128.60, 128.01, 127.44, 127.34, 126.96, 123.90, 123.79, 122.50, 115.92, 55.82. ESI HRMS: calcd. for $\mathrm{C}_{44} \mathrm{H}_{33} \mathrm{NO}_{2} \mathrm{~S}$ $[\mathrm{M}]^{+}:$639.2232, found: 639.2250.

4c was isolated as yellow solid with $85 \%$ yield. ${ }^{1} \mathrm{H}$ NMR (400 MHz, $\mathrm{CD}_{2} \mathrm{Cl}_{2}$ ): 9.84 (s, $\left.1 \mathrm{H}\right), 7.72$ (s, 1H), 7.53 (s, 2H), 6.89-7.33 (m, 36H). $\left.{ }^{13} \mathrm{C} \mathrm{NMR} \mathrm{(100} \mathrm{MHz,} \mathrm{CD}_{2} \mathrm{Cl}_{2}\right)$ : 183.03, 144.64, 144.47, 144.30, 144.09, 141.85, 141.41, 141.12, 138.39, 132.75, 131.82, 131.78, 129.78, 128.20, 128.16, 127.64, 126.99, 126.90, 125.59, 124.51, 123.43. ESI HRMS: calcd. for $\mathrm{C}_{55} \mathrm{H}_{40} \mathrm{~N}_{2} \mathrm{OS}[\mathrm{M}]^{+}:$776.2861, found: 776.2847 .

TPE-TTMN was isolated as dark brown solid with 78\% yield. ${ }^{1} \mathrm{H}$ NMR (400 MHz, CDCl 3 ): 7.74 (s, 1H), 7.67 (d, $J=4.0 \mathrm{~Hz}, 1 \mathrm{H}), 7.51$ (d, $J=8.8 \mathrm{~Hz}, 2 \mathrm{H}), 7.27-7.33$ (m, 3H), 6.93-7.16 (m, 22H), 6.85 (d, $J=8.4 \mathrm{~Hz}, 2 \mathrm{H}) .{ }^{13} \mathrm{C}$ NMR (100 $\left.\mathrm{MHz} \mathrm{CDCl}_{3}\right):$ 157.10, 150.27, 149.66, 146.38, 144.64, 143.49, 143.30, 141.08, 140.42, 140.34, 139.74, 133.05, 132.44, 131.34, 131.28, 129.48, 127.70, 127.63, 127.59, 127.48, 126.53, 126.49, 126.44, 125.42, 124.83, 124.28, 124.25, 123.22, 121.81, 114.56, 113.68. ESI HRMS: calcd. for $\mathrm{C}_{46} \mathrm{H}_{31} \mathrm{~N}_{3} \mathrm{~S}[\mathrm{M}]^{+}: 657.2239$, found: 657.2275.

TPE-TTMN-OMe was isolated as dark brown solid with 75\% yield. ${ }^{1} \mathrm{H}$ NMR (400 $\left.\mathrm{MHz}, \mathrm{CDCl}_{3}\right)$ : 7.73 (s, 1H), 7.66 (d, $J=4.4 \mathrm{~Hz}, 1 \mathrm{H}$ ), 7.48 (d, $J=4.4 \mathrm{~Hz}, 2 \mathrm{H}), 7.30$ (d, $J=4.0 \mathrm{~Hz}, 1 \mathrm{H}), 7.01-7.16$ (m, 17H), 6.82-6.94 (m, 8H), 3.82 (s, 3H). ${ }^{13} \mathrm{C} \mathrm{NMR} \mathrm{(100} \mathrm{MHz,} \mathrm{CDCl} 3$ ): 157.33, 156.98, 150.19, 149.96, 144.68, 143.83, 143.53, 143.35, 140.91, 140.51, 140.35, 139.23, 139.07, 132.81, 132.32, 131.31, 131.27, 127.83, 127.65, 127.58, 127.42, 126.45, 126.37, 124.02, 123.48, 122.98, 120.55, 114.93, 114.62, 113.74, 74.55, 55.45. ESI HRMS: calcd. for $\mathrm{C}_{47} \mathrm{H}_{33} \mathrm{~N}_{3} \mathrm{OS}[\mathrm{M}]^{+}$: 687.2344, found: 687.2327.

TPE-TTMN-TPA was isolated as dark brown solid with $68 \%$ yield. ${ }^{1} \mathrm{H}$ NMR (400 $\mathrm{MHz}, \mathrm{CD}_{2} \mathrm{Cl}_{2}$ ): 7.79 (s, 1H), 7.69 (d, $J=4.0 \mathrm{~Hz}, 1 \mathrm{H}), 7.55$ (d, $J=8.8 \mathrm{~Hz}, 2 \mathrm{H}), 7.36$ (d, $J=4.0 \mathrm{~Hz}, 1 \mathrm{H}), 7.25-7.29$

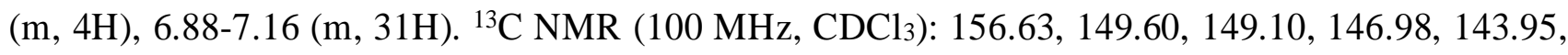
143.79, 143.23, 142.91, 142.75, 140.41, 140.09, 139.82, 139.75, 138.95, 132.33, 131.81, 130.74, 130.69, 130.68, 128.66, 127.09, 127.01, 126.98, 126.87, 125.98, 125.90, 125.87, 125.82, 124.09, 123.84, 123.56, 123.35, 122.47, 122.25, 120.64, 114.0, 74.17. ESI HRMS: calcd. for $\mathrm{C}_{58} \mathrm{H}_{40} \mathrm{~N}_{4} \mathrm{~S}[\mathrm{M}]^{+}$: 824.2974, found: 824.2974. 
NMR and HRMS spectra
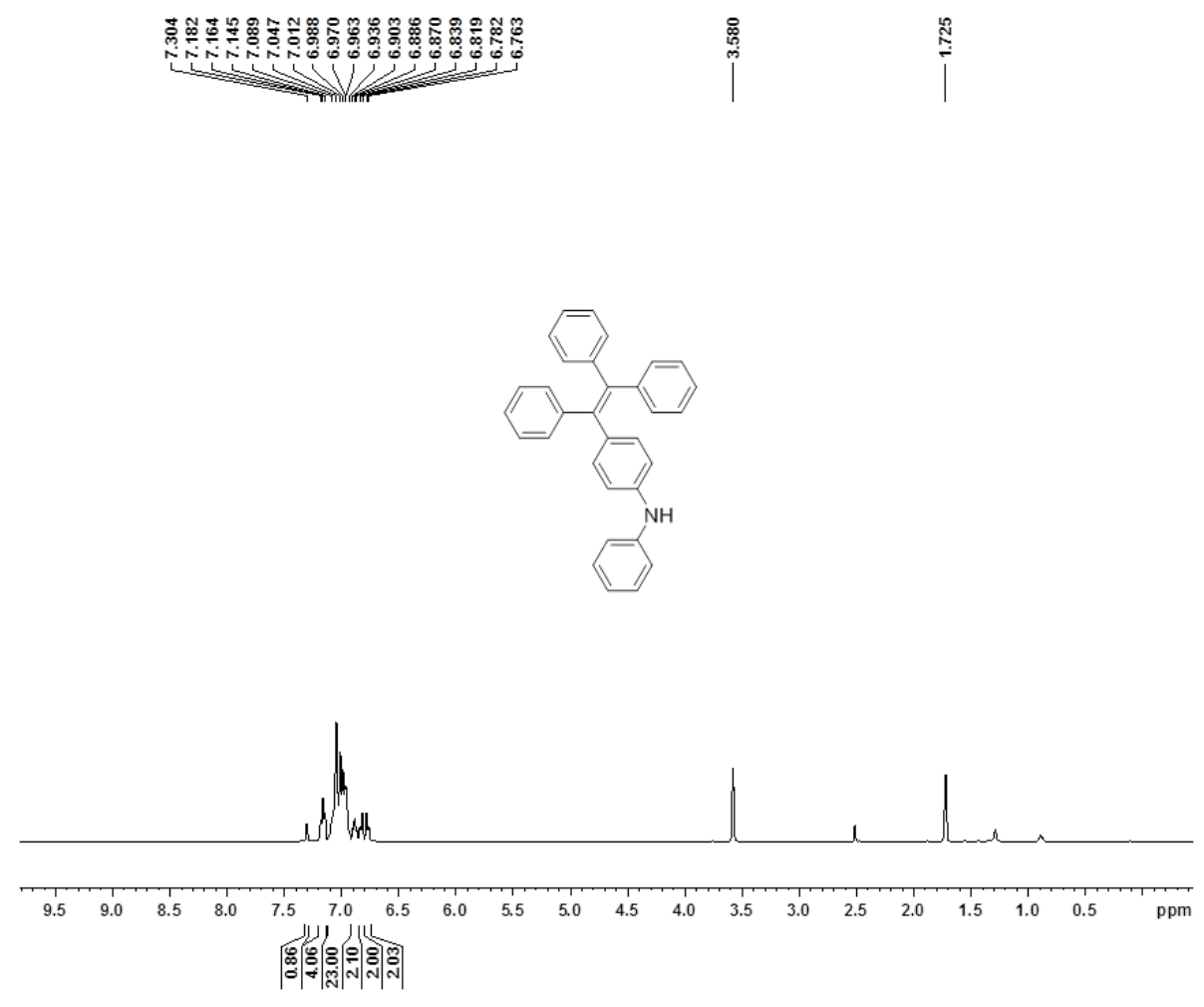

Figure S2. ${ }^{1} \mathrm{H}$ NMR spectrum of 2 a.

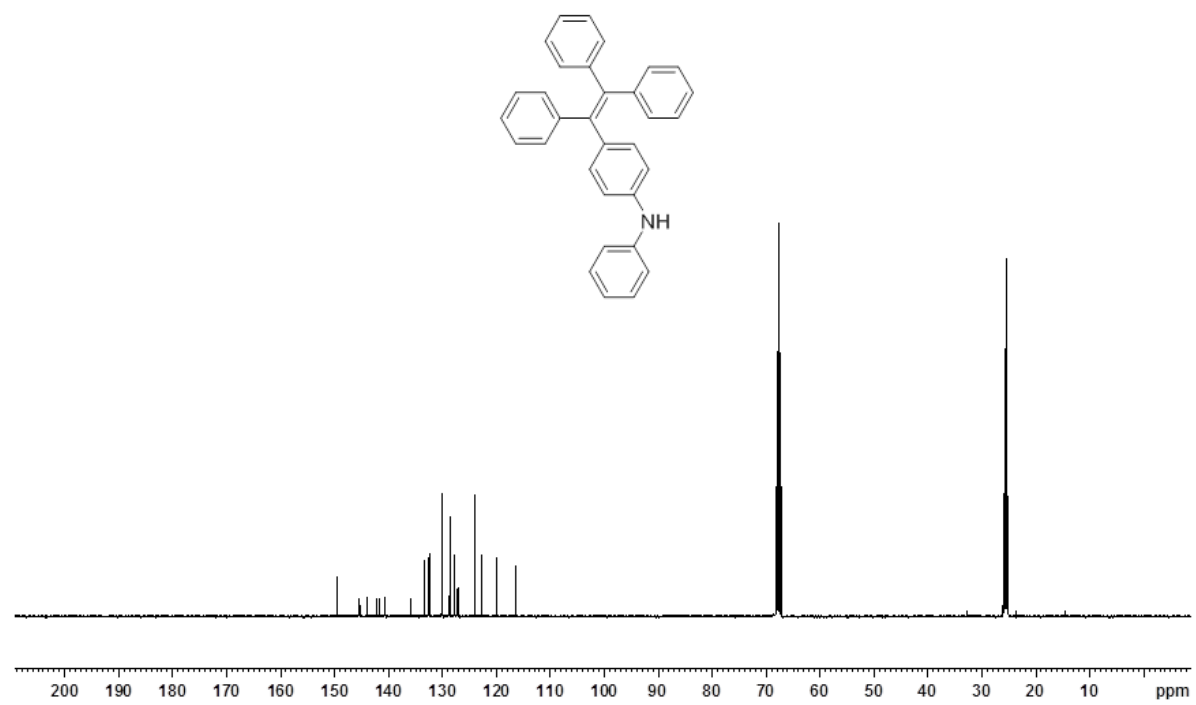

Figure S3. ${ }^{13} \mathrm{C}$ NMR spectrum of $\mathbf{2 a}$. 

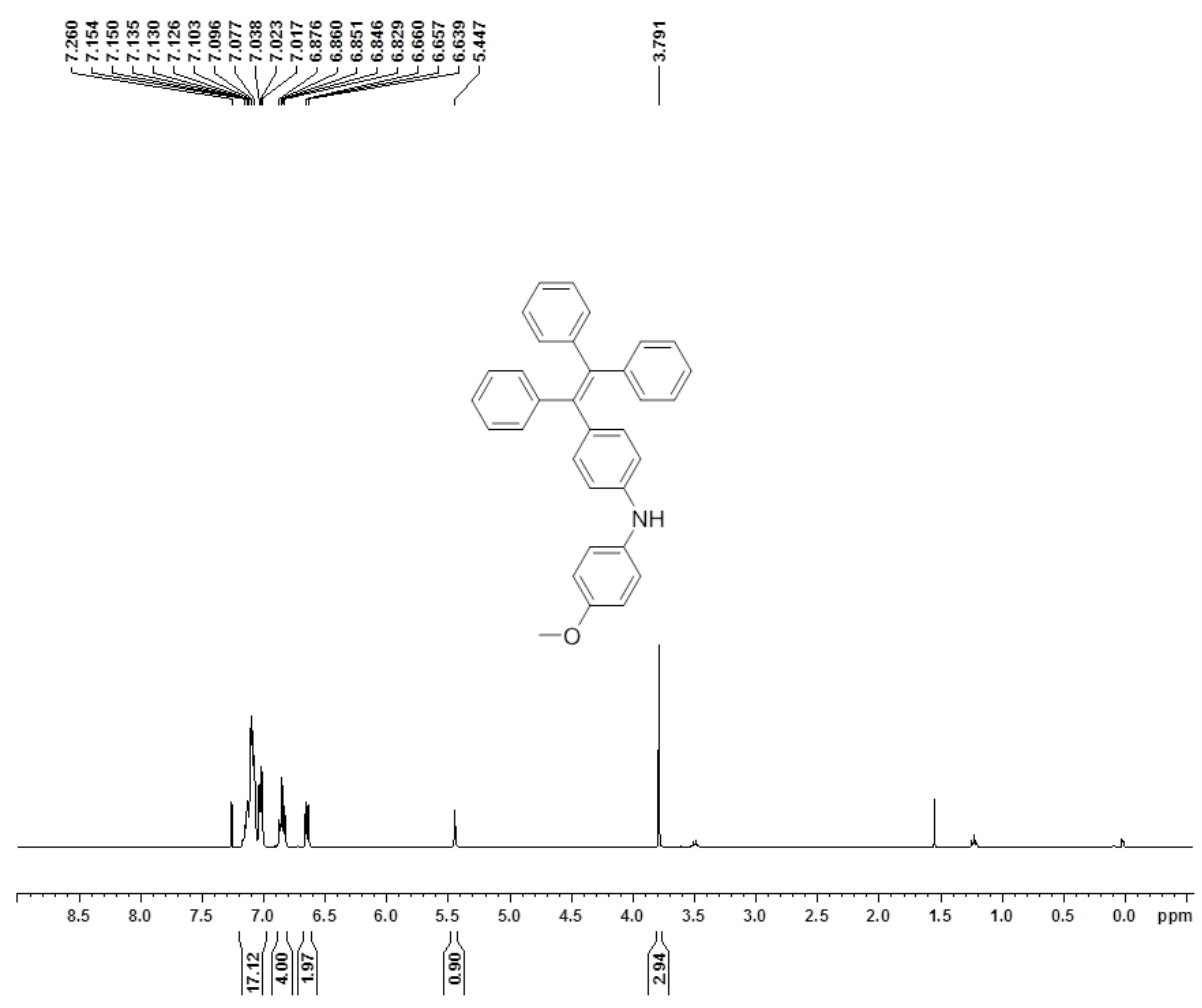

Figure S4. ${ }^{1} \mathrm{H}$ NMR spectrum of $\mathbf{2 b}$.
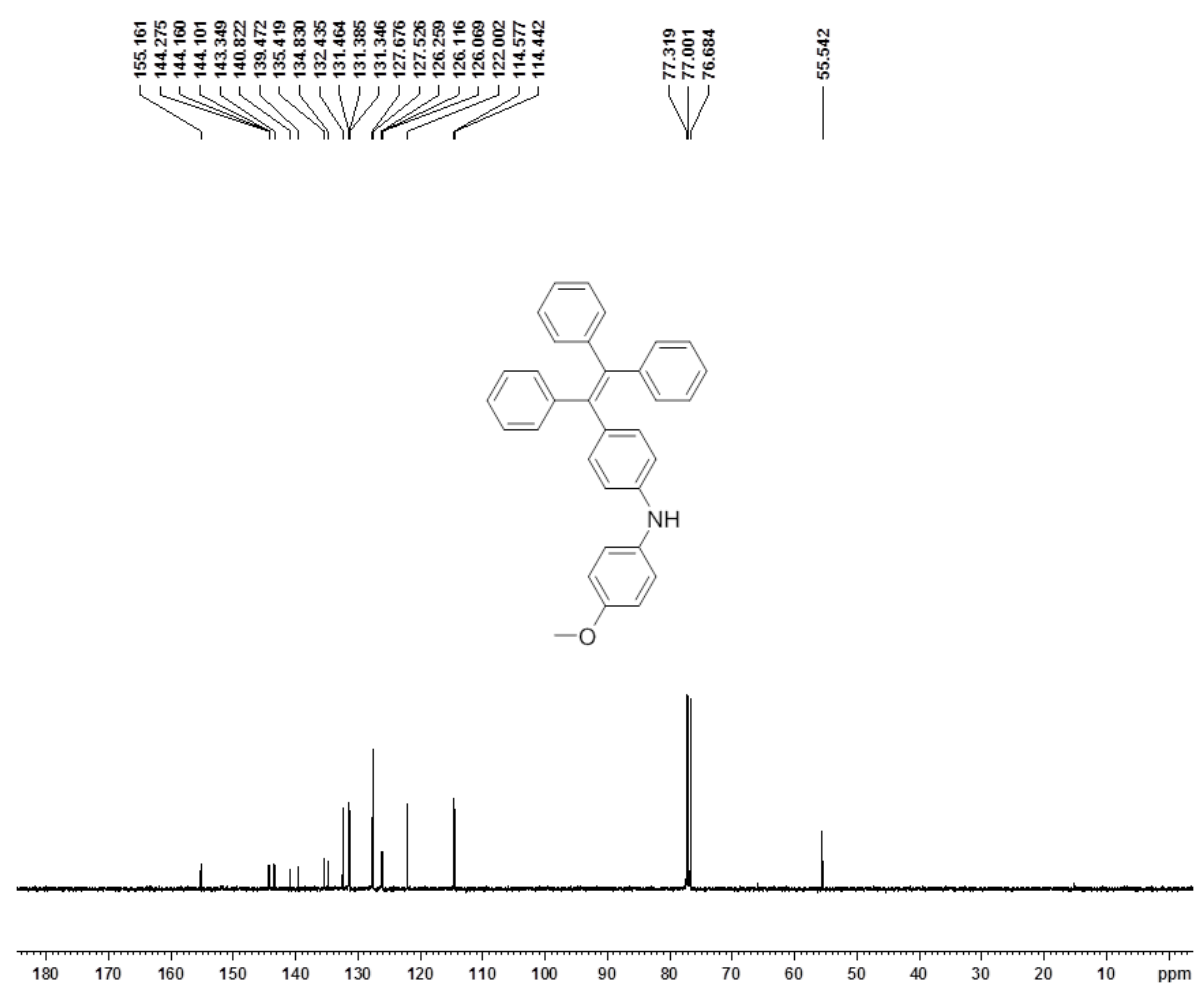

Figure S5. ${ }^{13} \mathrm{C}$ NMR spectrum of $\mathbf{2 b}$. 


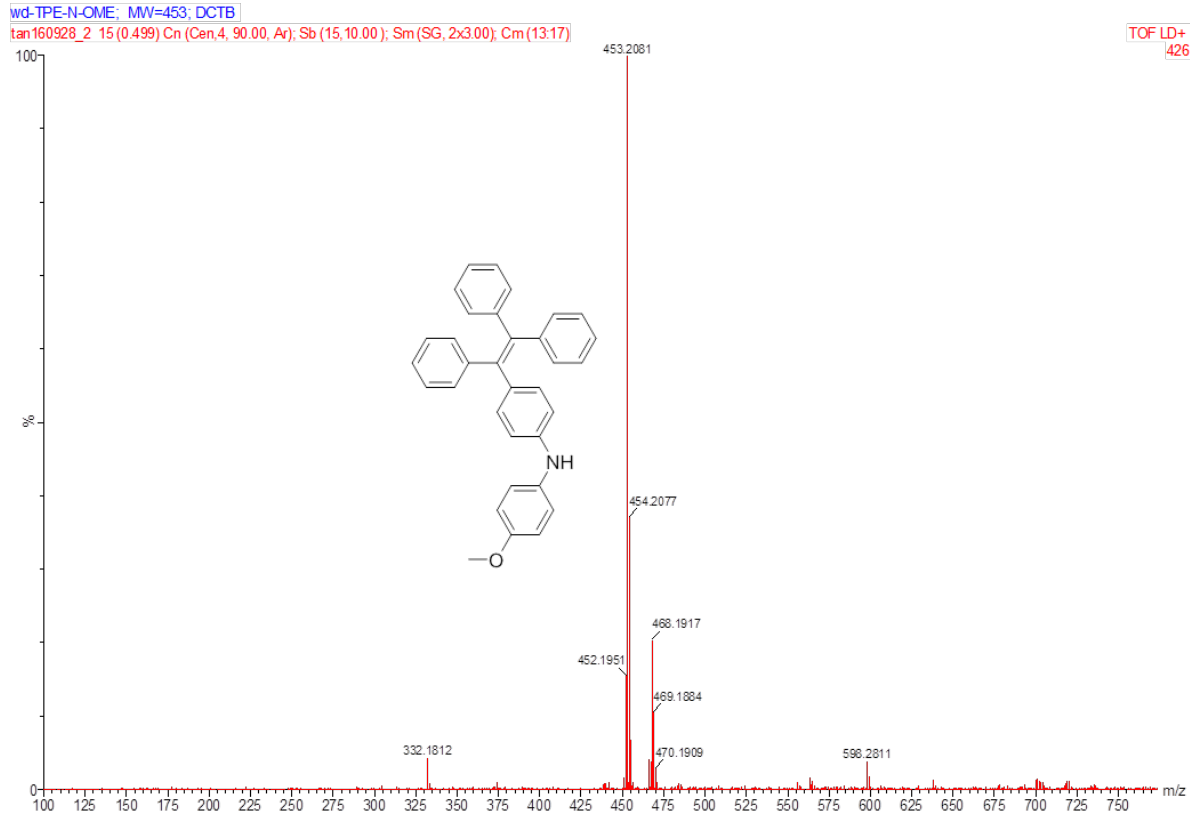

Figure S6. ESI HRMS spectrum of $\mathbf{2 b}$.

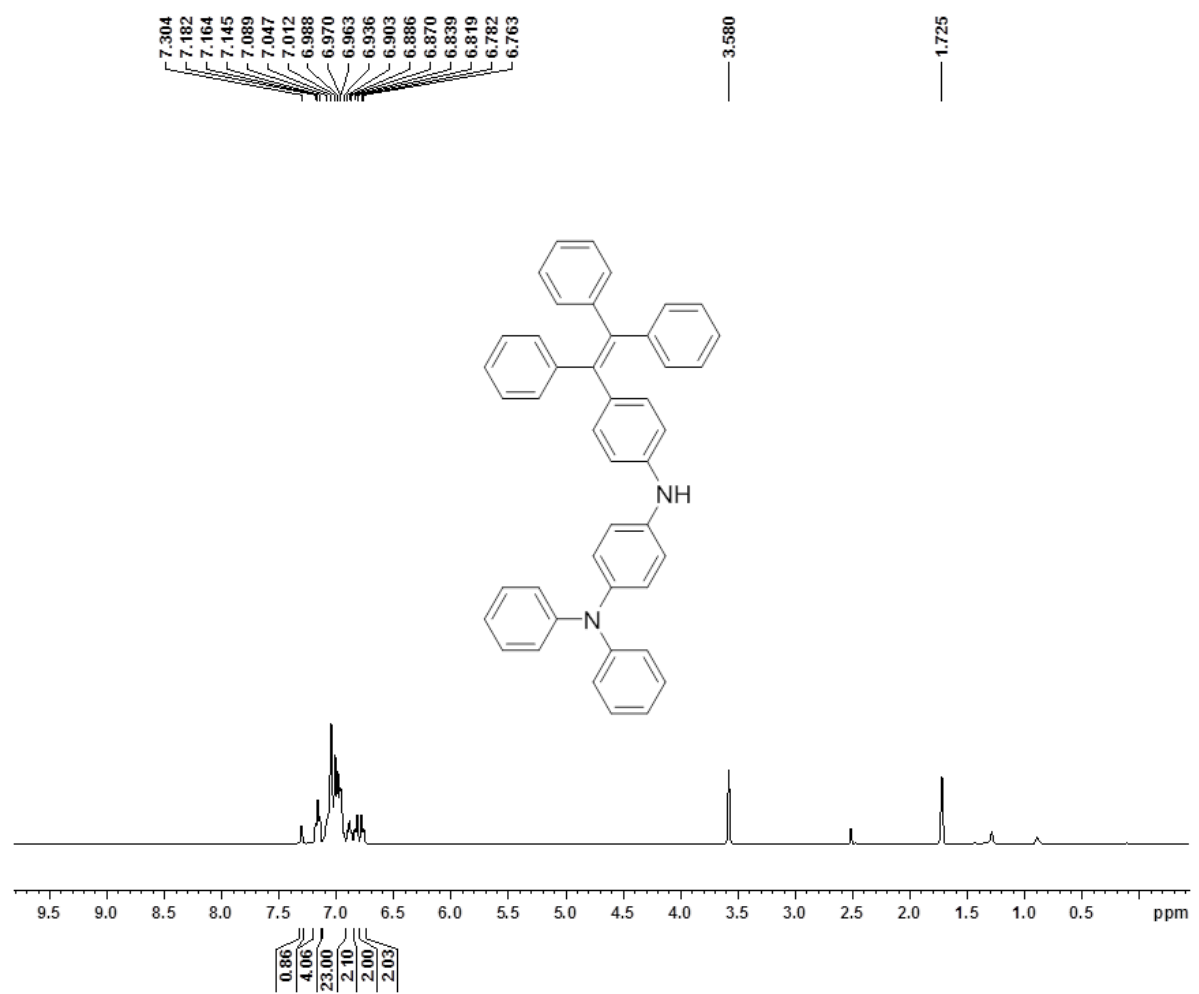

Figure S7. ${ }^{1} \mathrm{H}$ NMR spectrum of 2 c. 


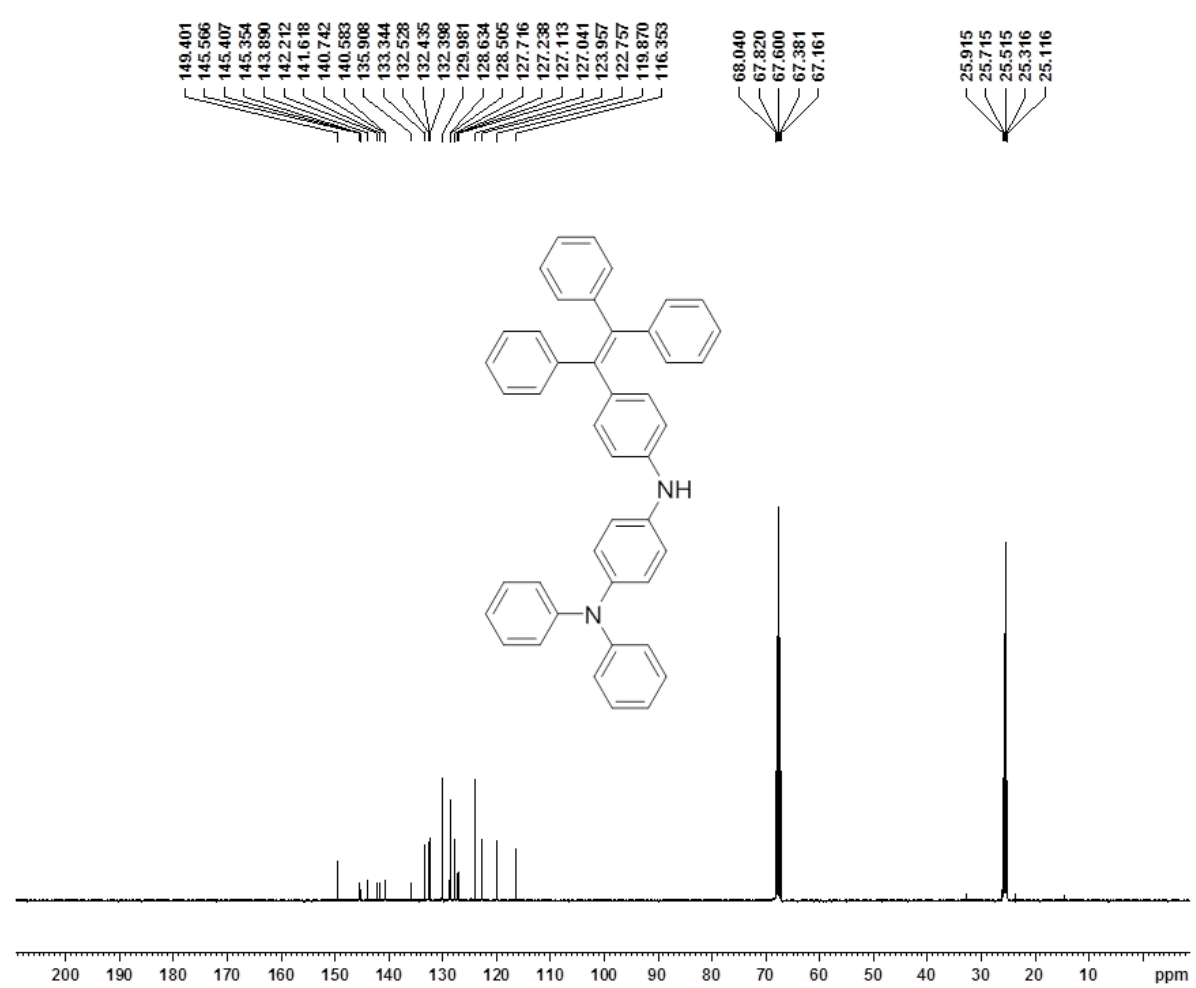

Figure S8. ${ }^{13} \mathrm{C}$ NMR spectrum of 2c.

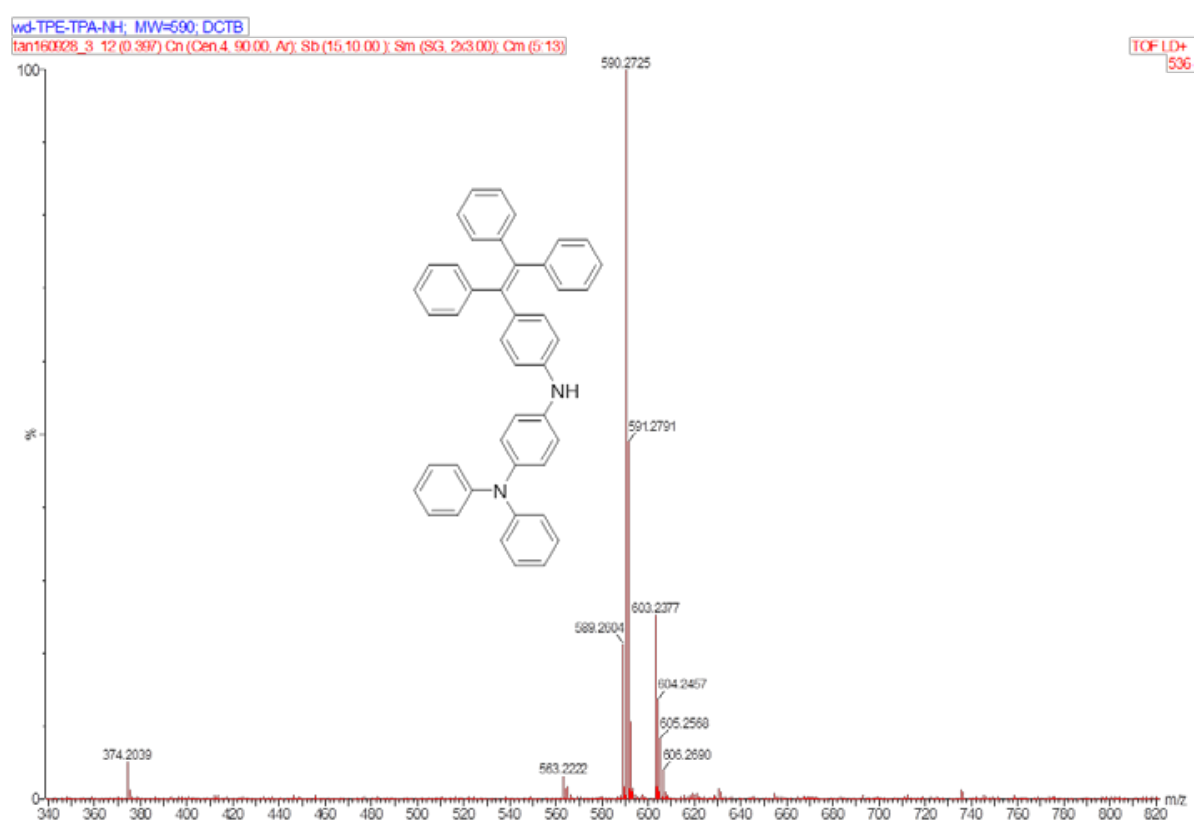

Figure S9. ESI HRMS spectrum of 2c. 


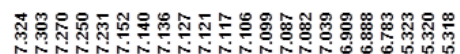

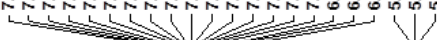
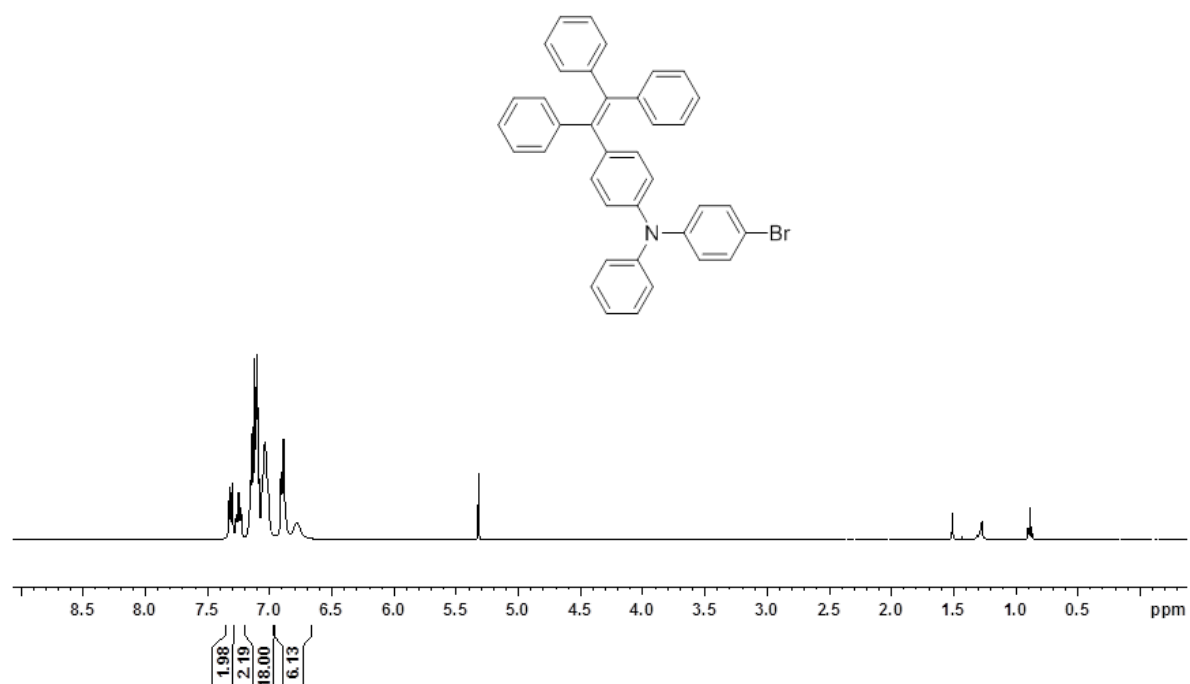

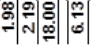

Figure S10. ${ }^{1} \mathrm{H}$ NMR spectrum of $\mathbf{3 a}$.

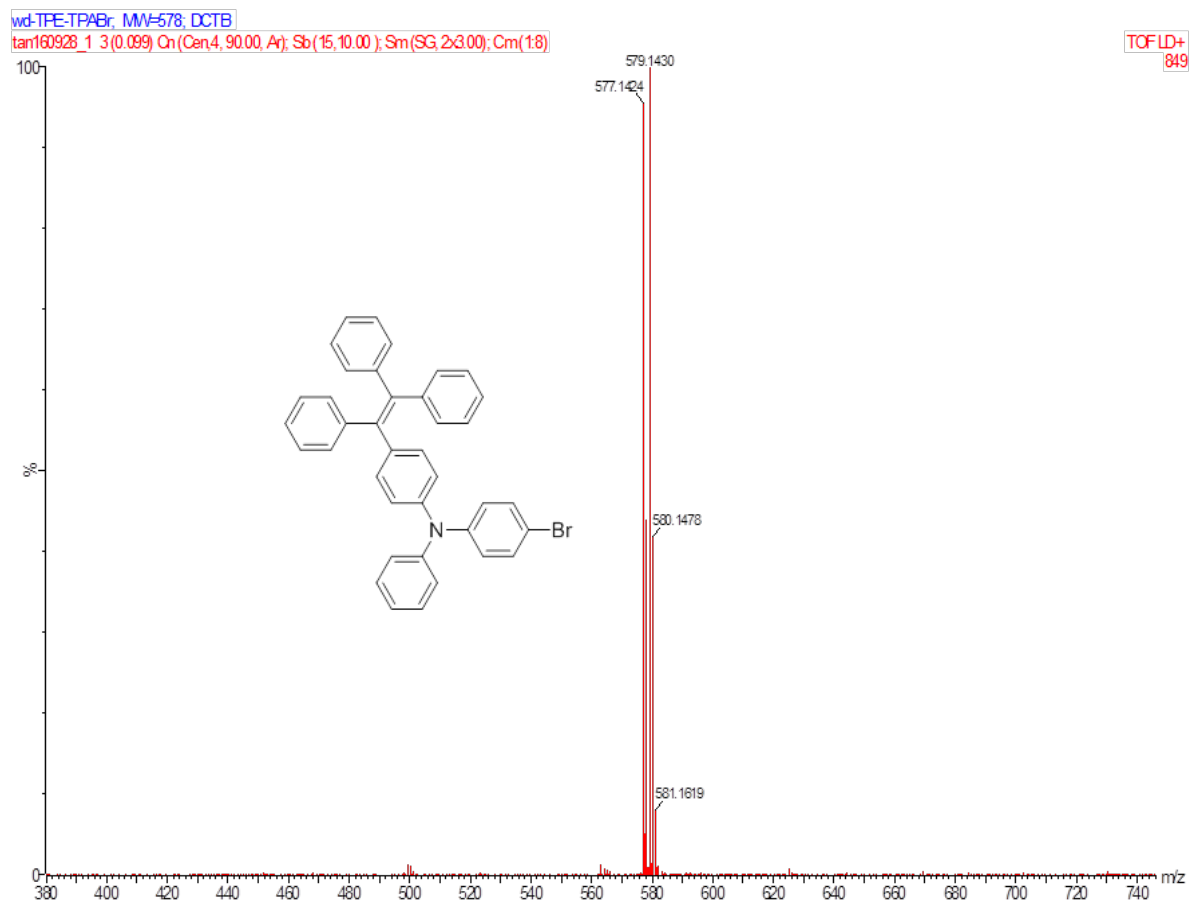


Figure S11. ESI HRMS spectrum of 3a.

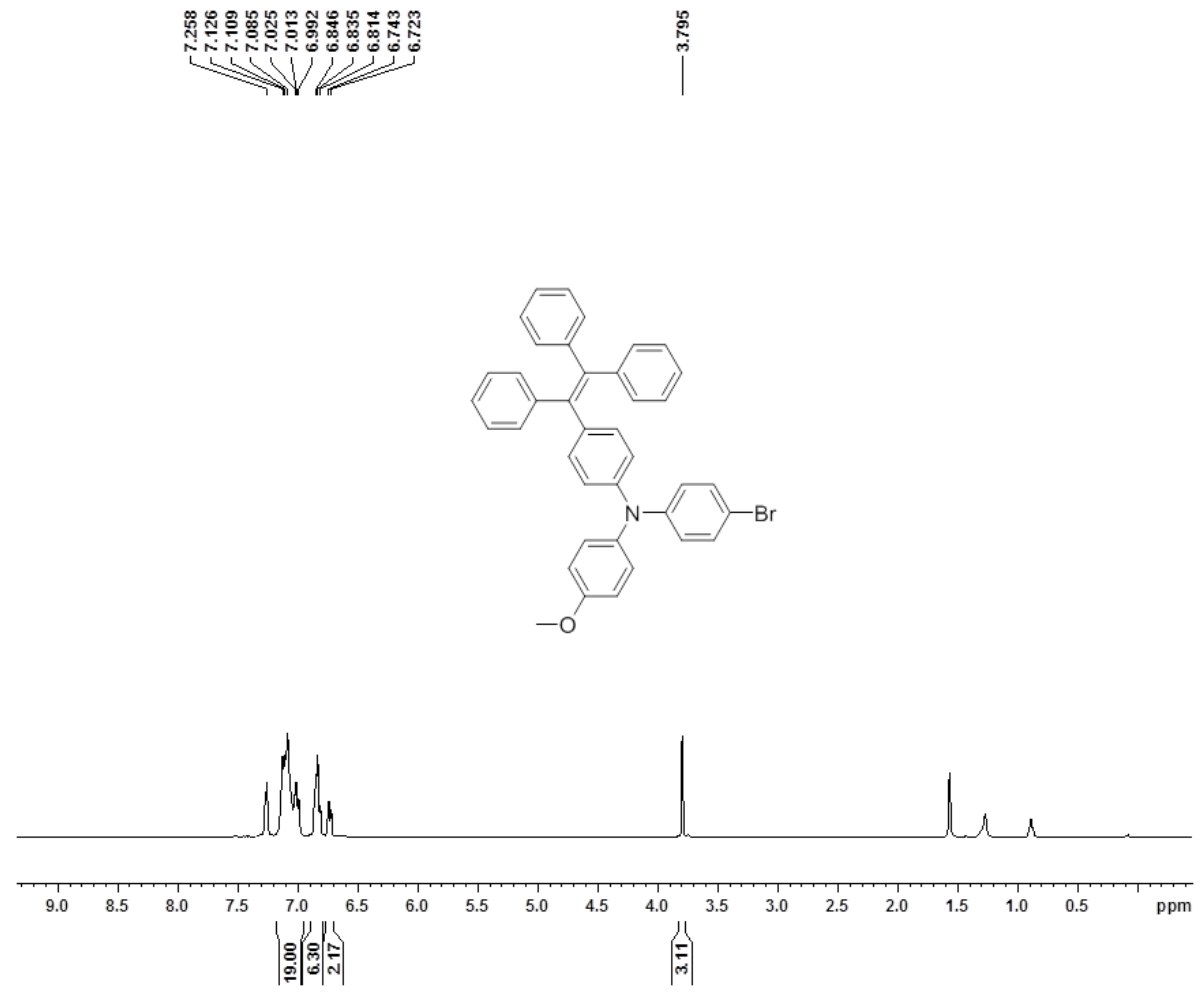

L 1

Figure S12. ${ }^{1} \mathrm{H}$ NMR spectrum of $\mathbf{3 b}$. 


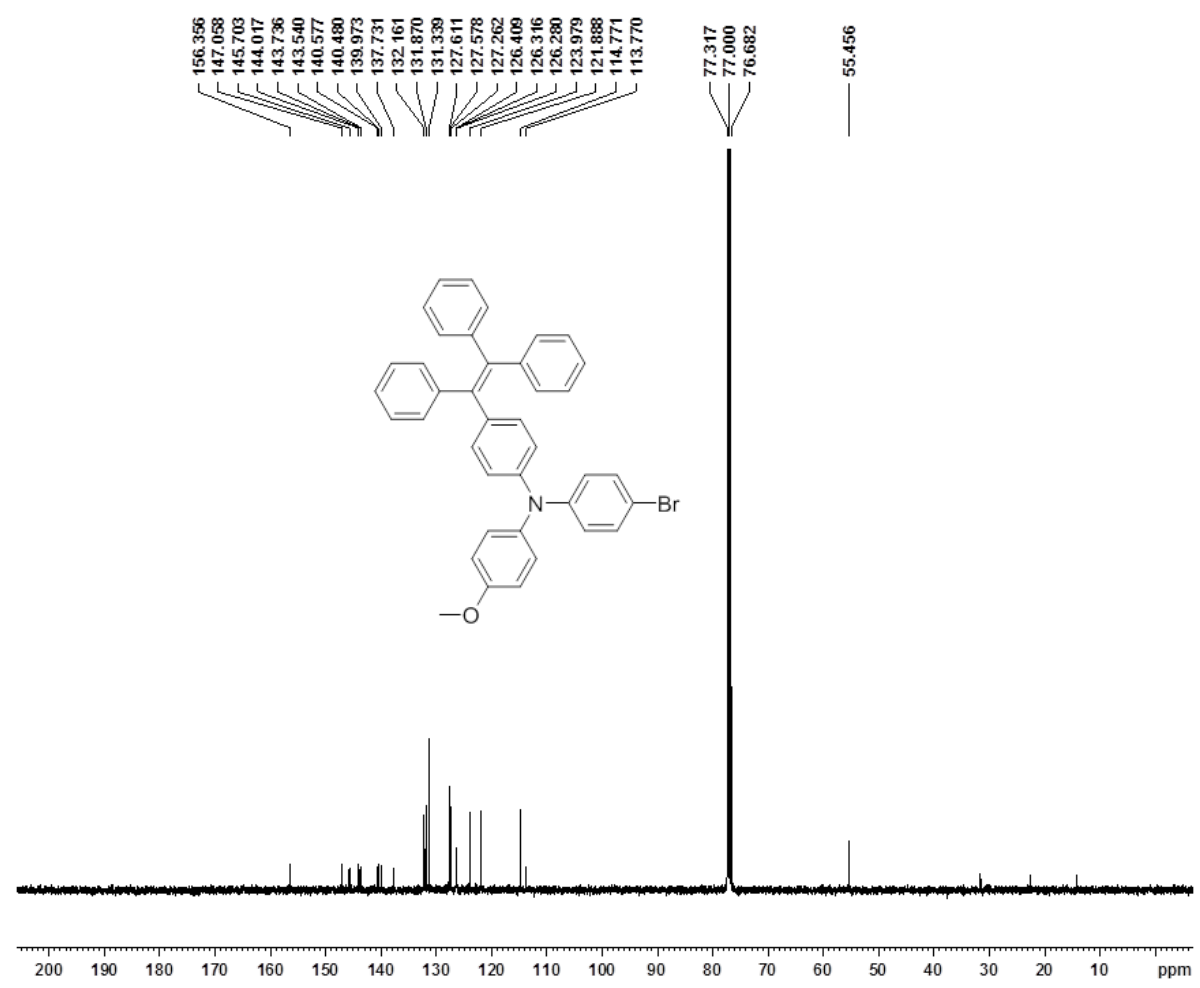

Figure S13. ${ }^{13} \mathrm{C}$ NMR spectrum of $\mathbf{3 b}$.

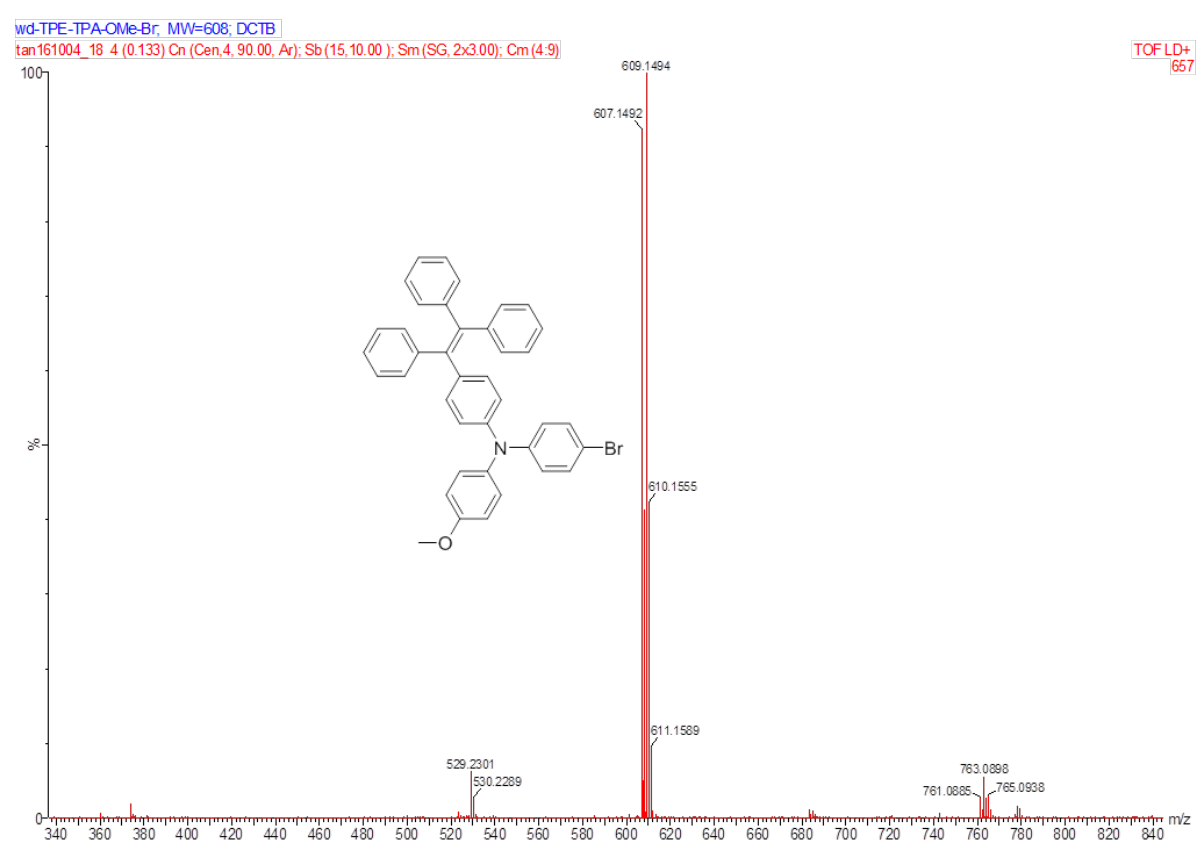

Figure S14. ESI HRMS spectrum of $\mathbf{3 b}$. 


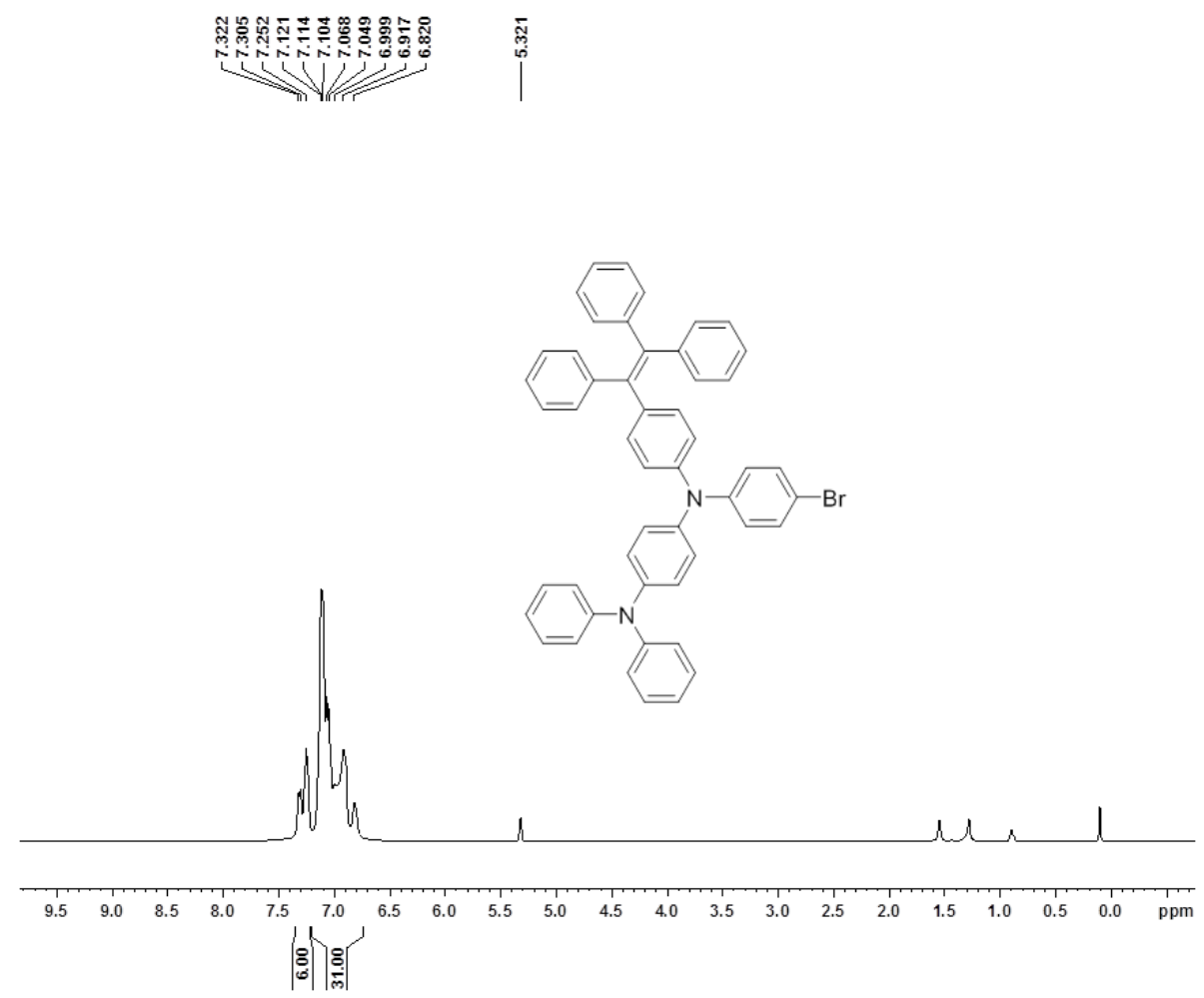

Figure S15. ${ }^{1} \mathrm{H}$ NMR spectrum of 3c.

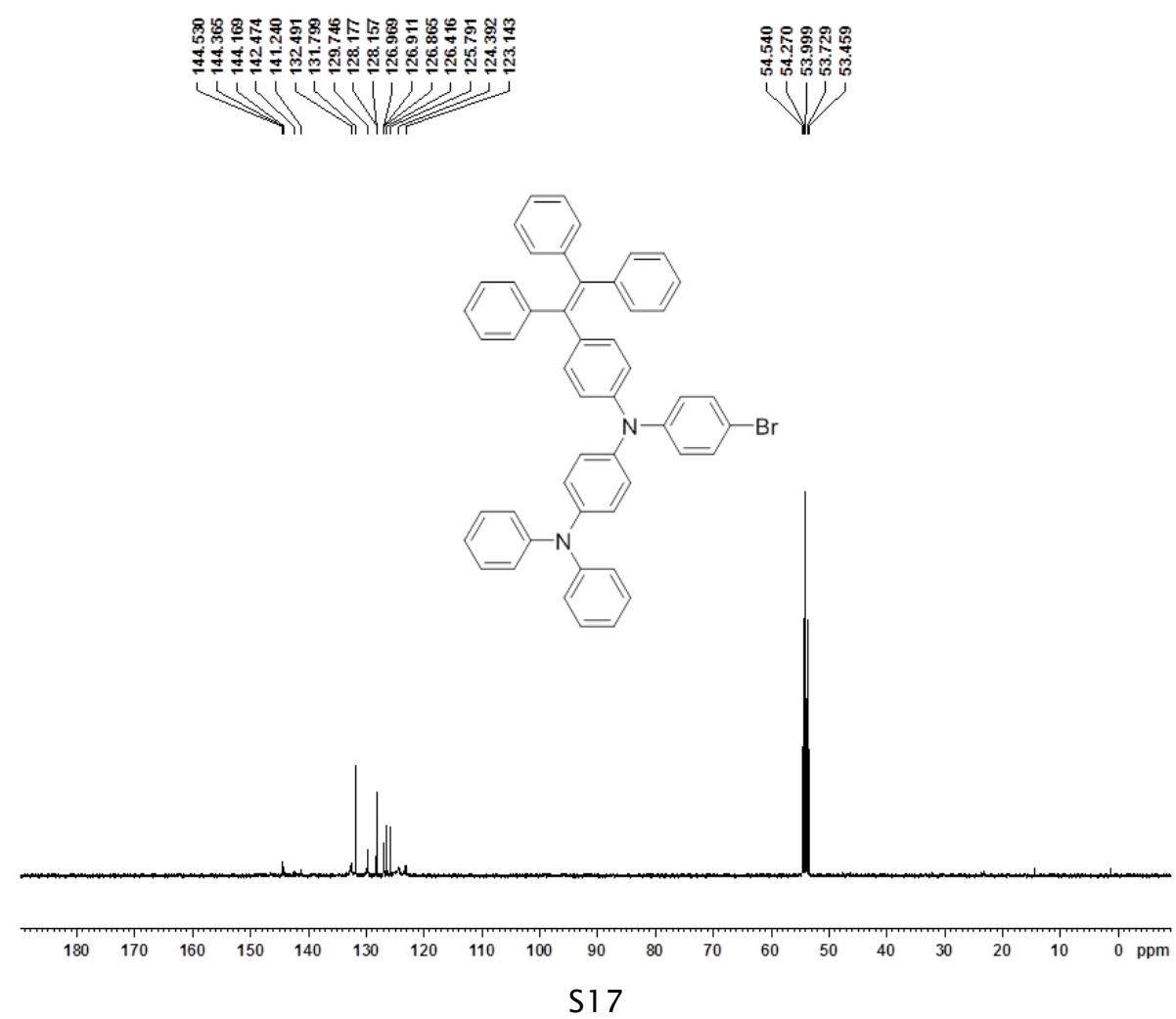


Figure S16. ${ }^{13} \mathrm{C}$ NMR spectrum of 3c.

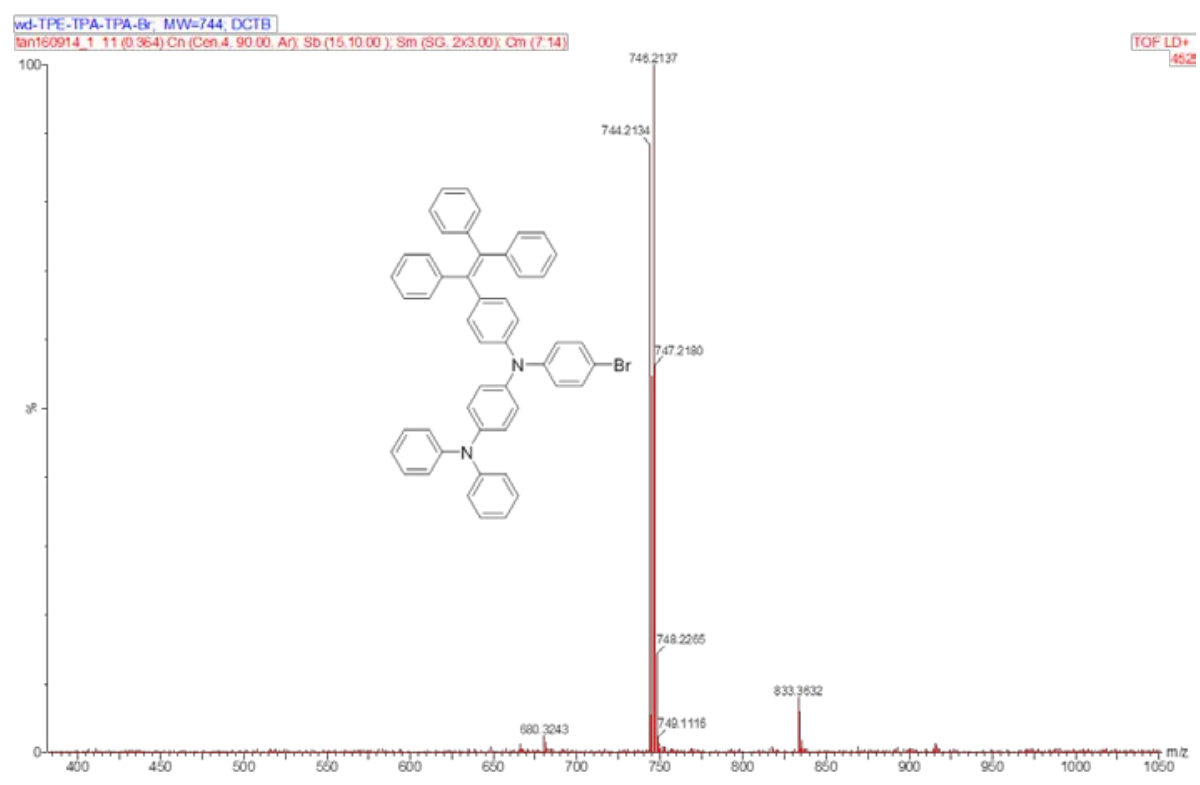

Figure S17. ESI HRMS spectrum of 3c.

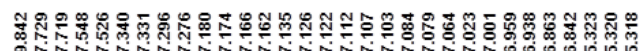
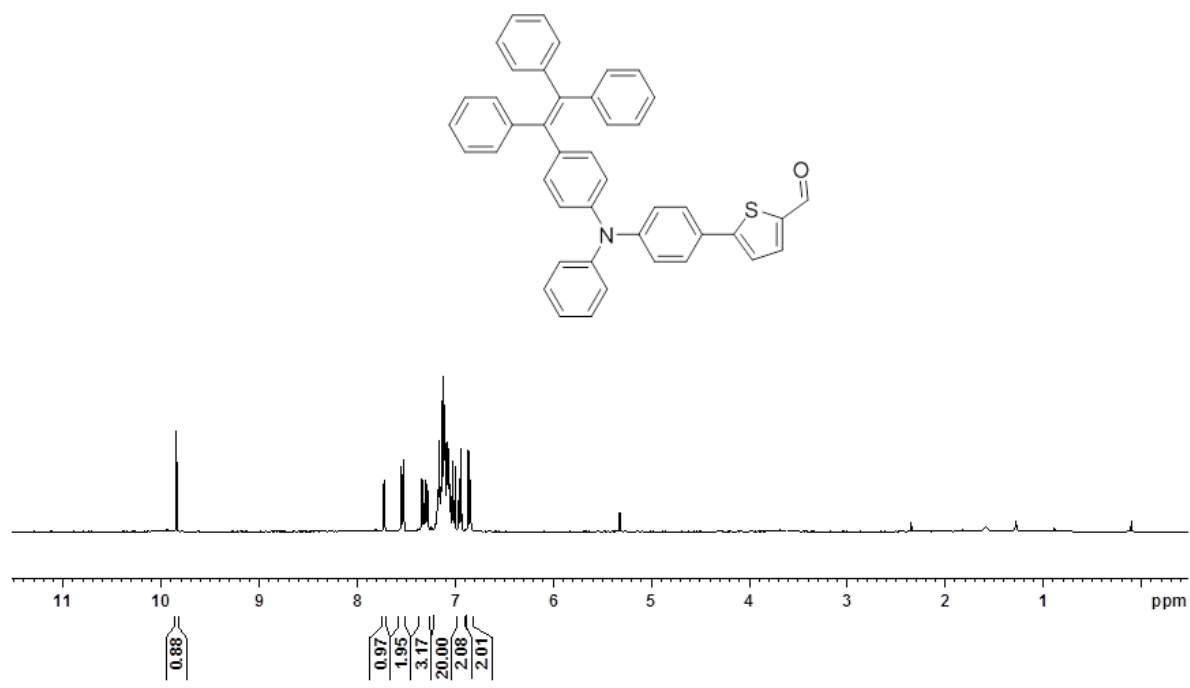
Figure S18. ${ }^{1} \mathrm{H}$ NMR spectrum of $\mathbf{4 a}$.

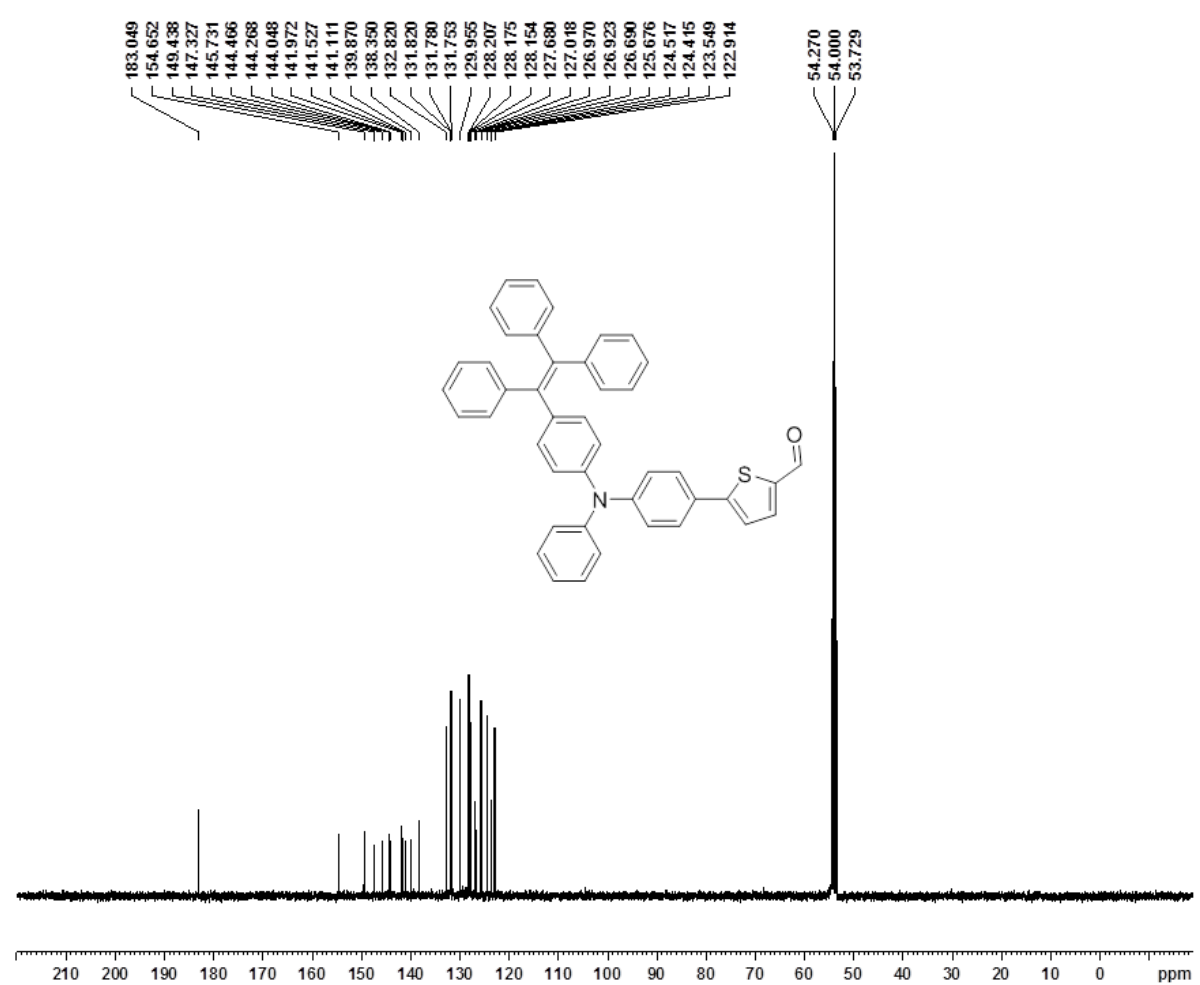

Figure S19. ${ }^{13} \mathrm{C}$ NMR spectrum of $\mathbf{4 a}$.

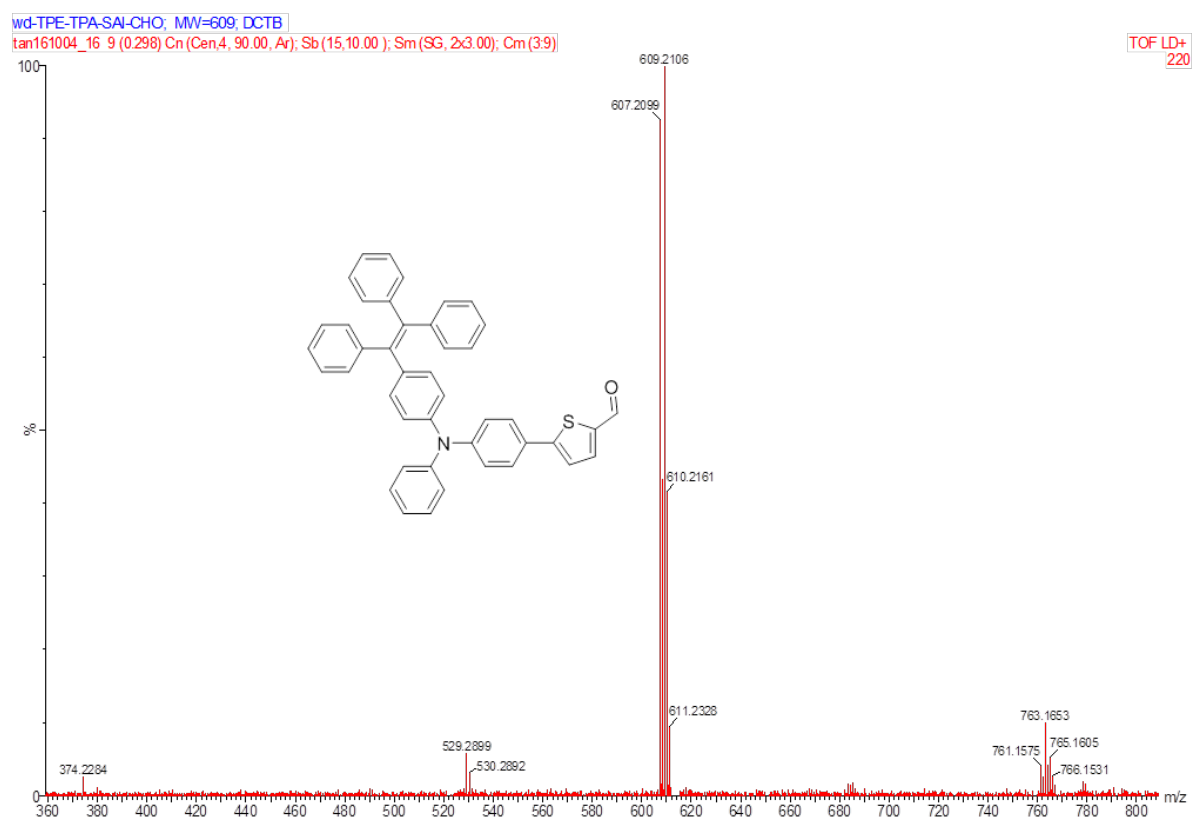

Figure S20. ESI HRMS spectrum of $\mathbf{4 a}$. 


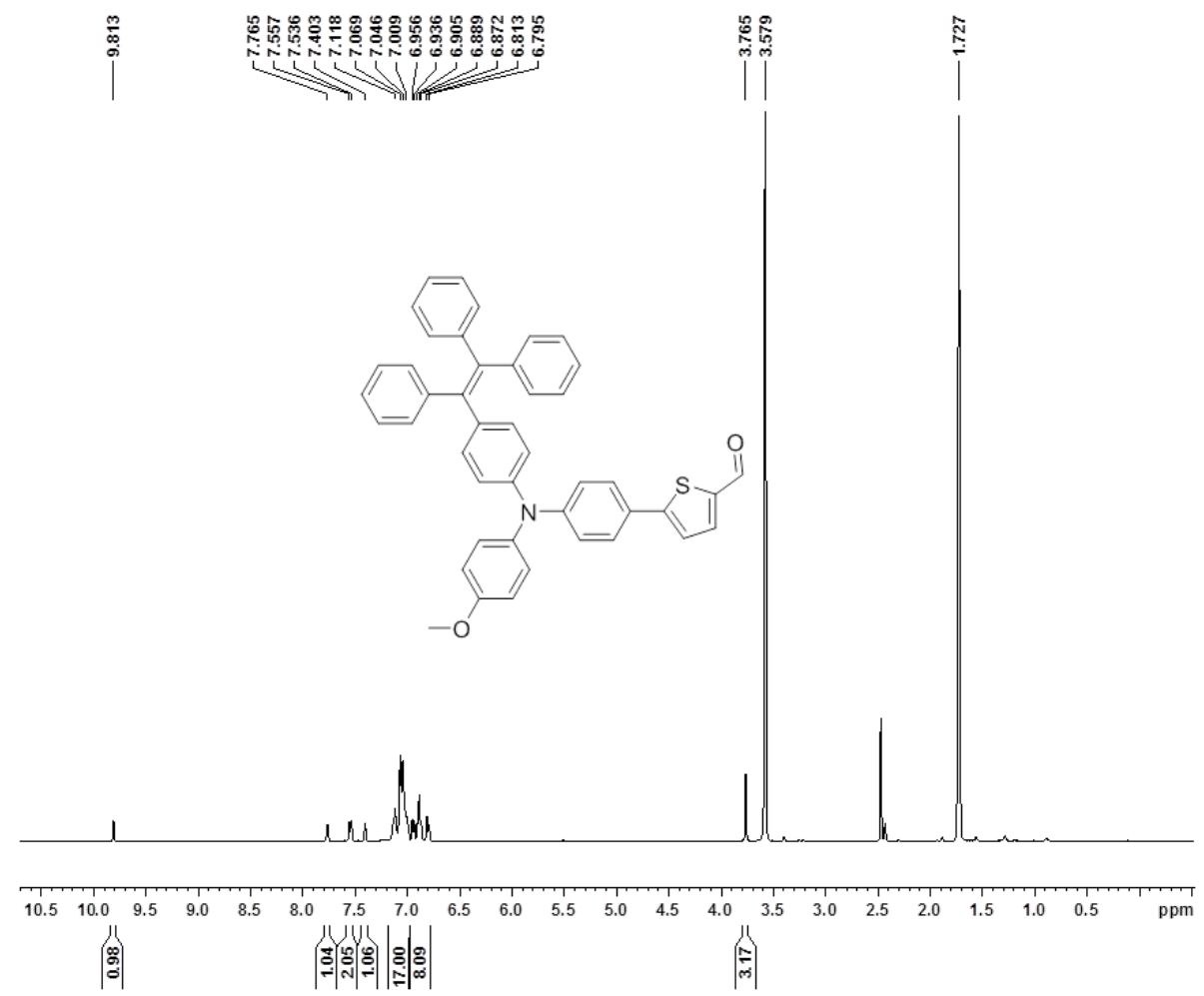

Figure S21. ${ }^{1} \mathrm{H}$ NMR spectrum of $\mathbf{4 b}$.

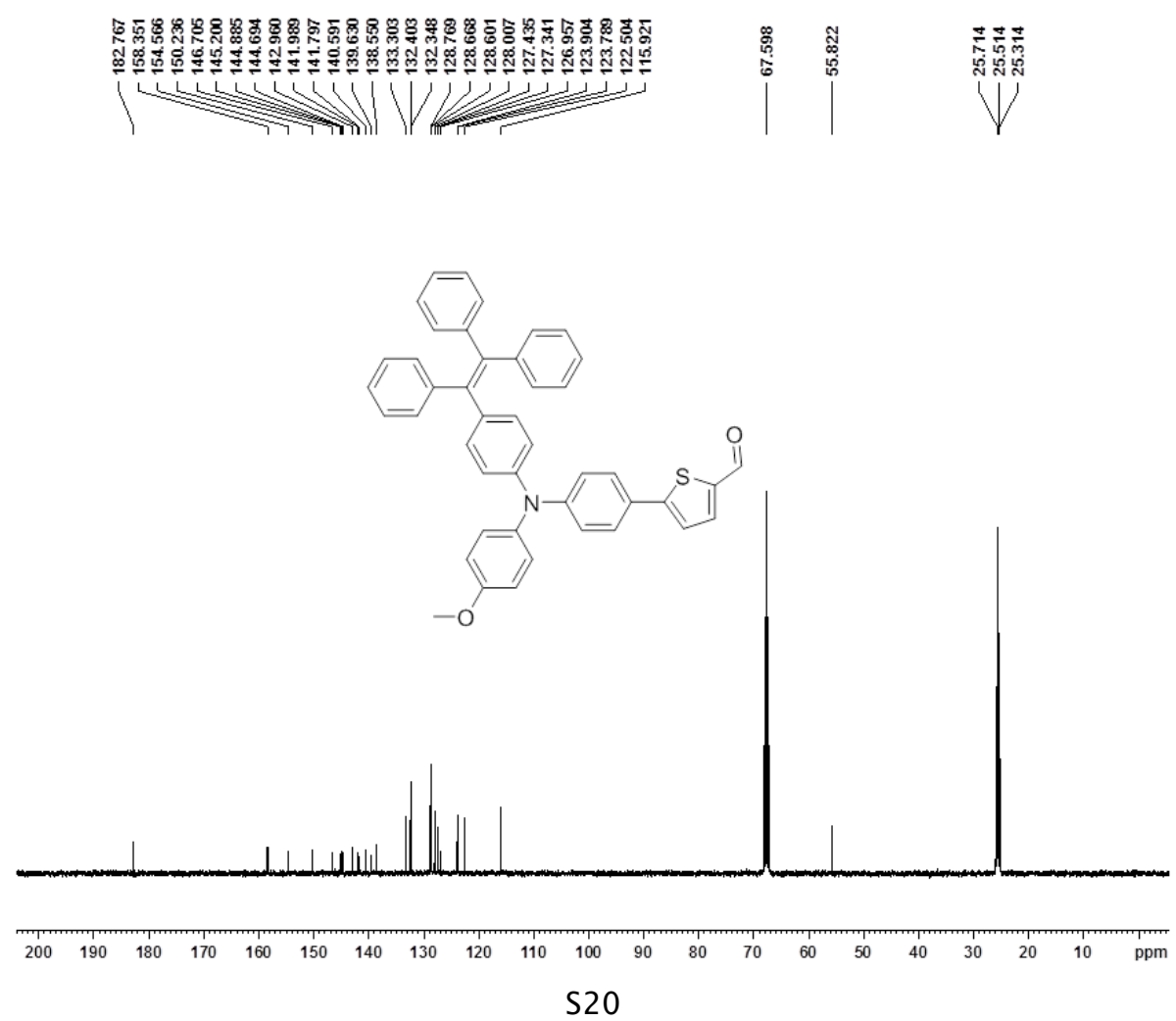


Figure S22. ${ }^{13} \mathrm{C}$ NMR spectrum of $\mathbf{4 b}$.

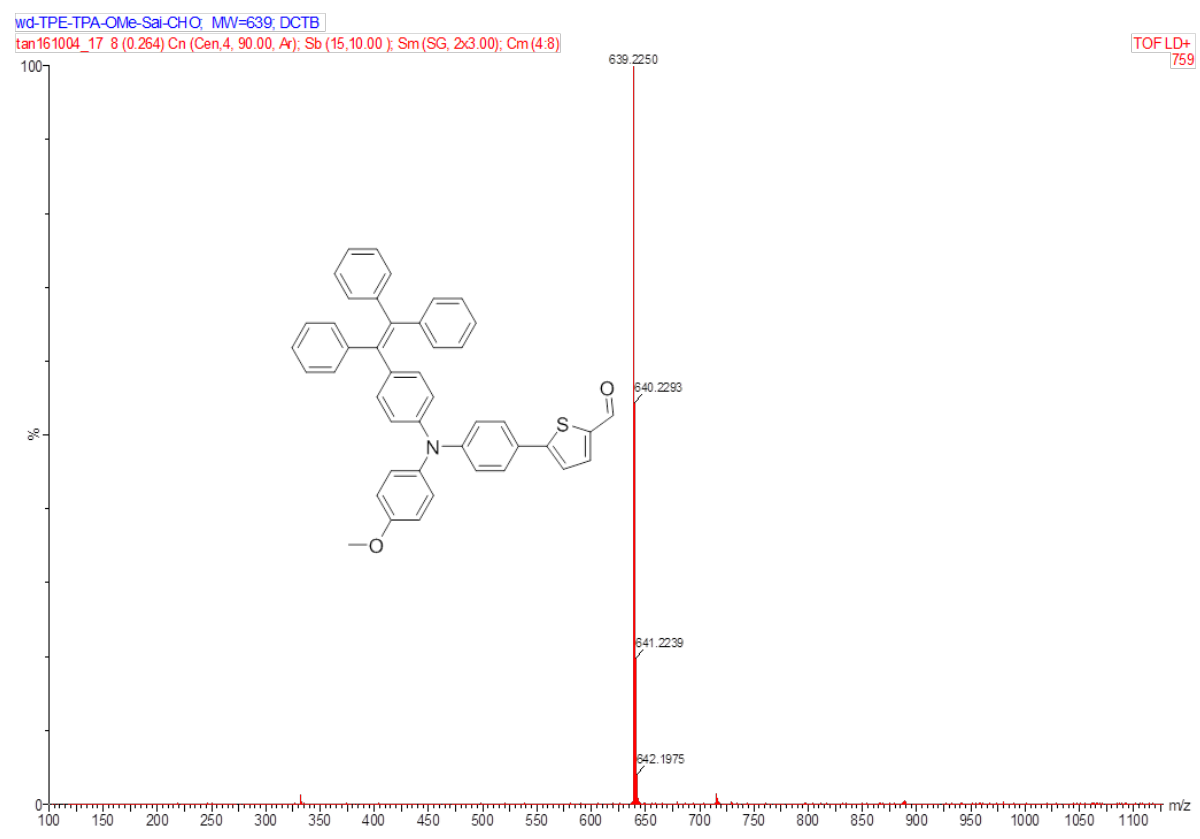

Figure S23. ESI HRMS spectrum of $\mathbf{4 b}$. 


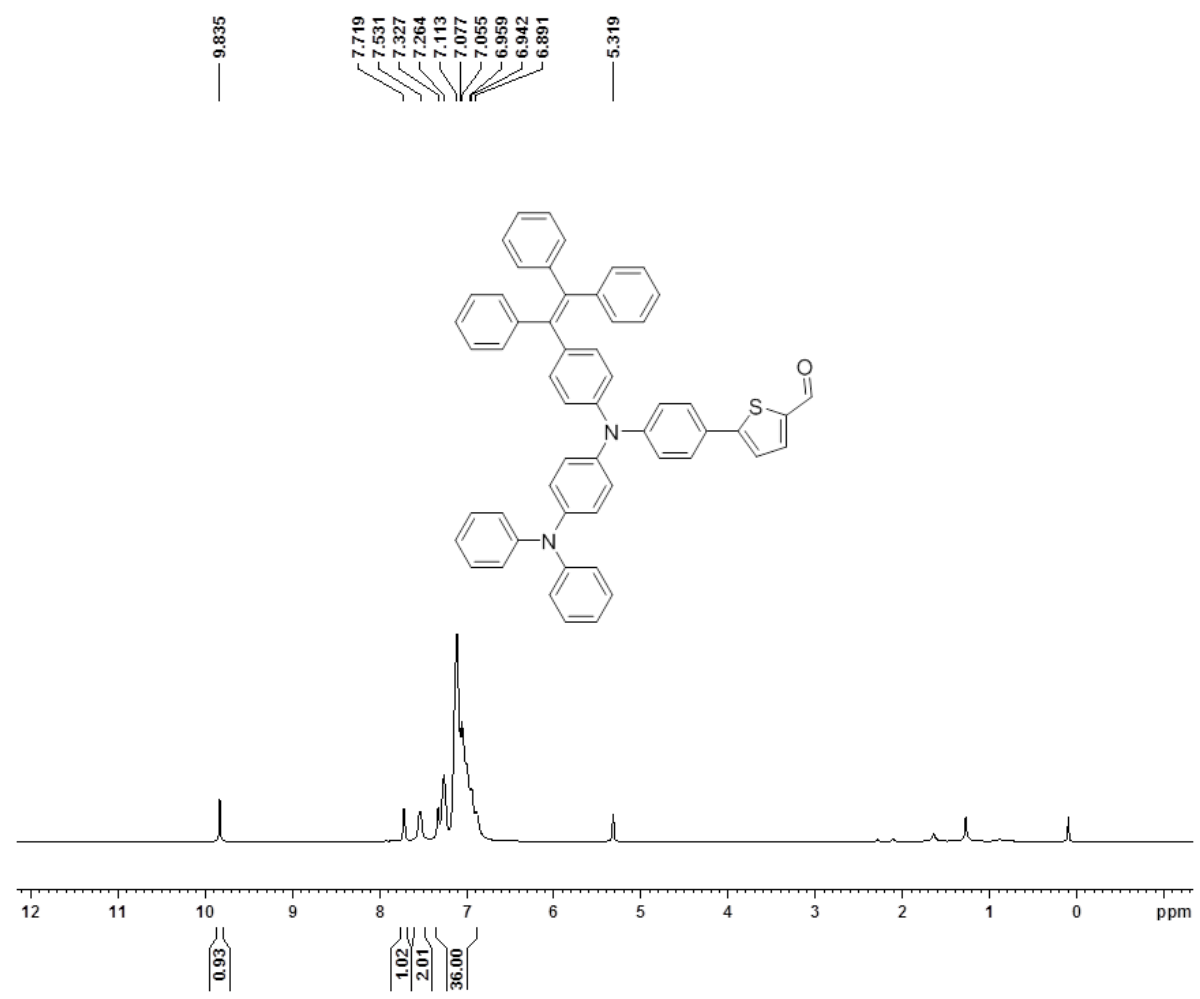

Figure S24. ${ }^{1} \mathrm{H}$ NMR spectrum of $\mathbf{4 c}$.

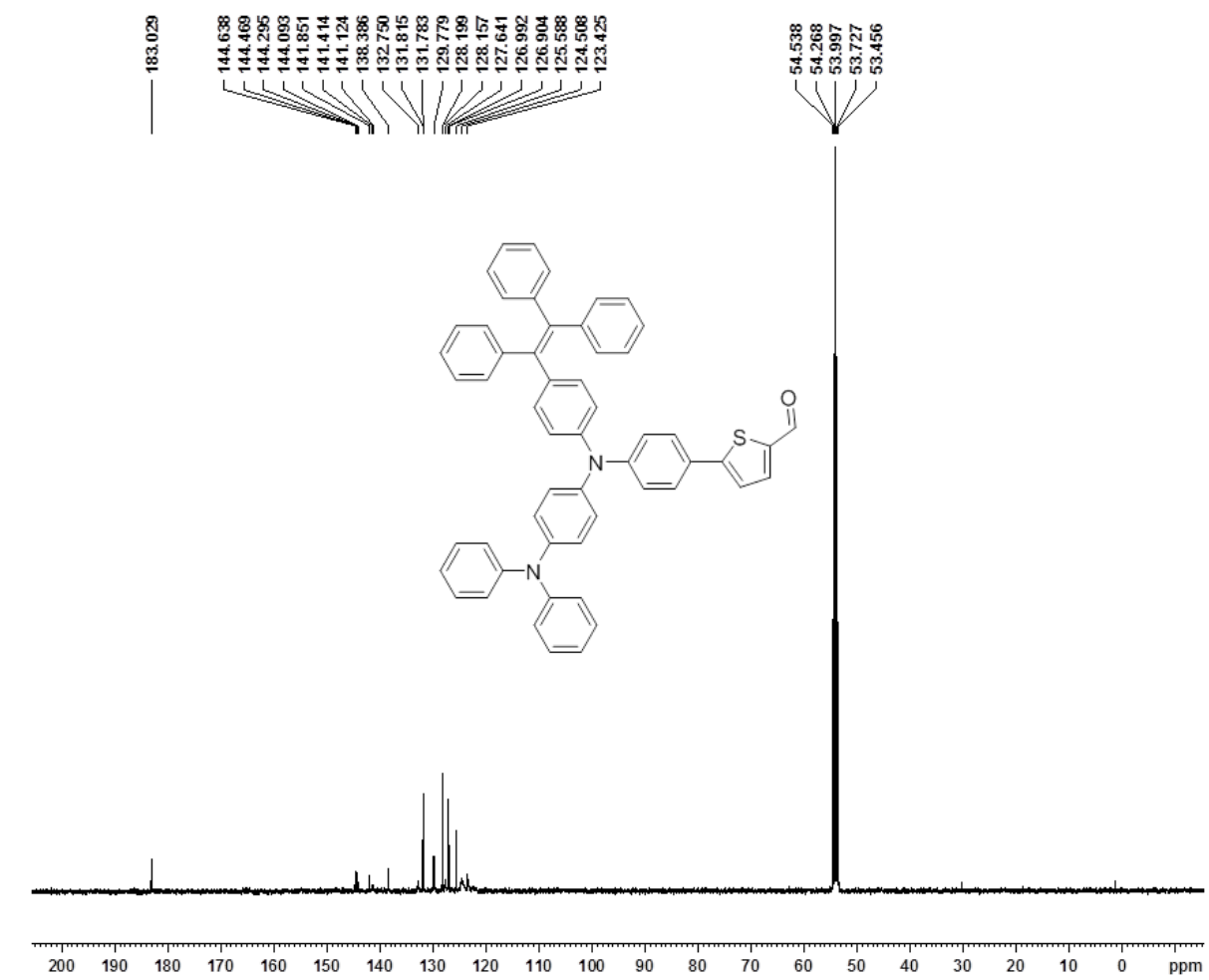

Figure S25. ${ }^{13} \mathrm{C}$ NMR spectrum of $\mathbf{4 c}$. 


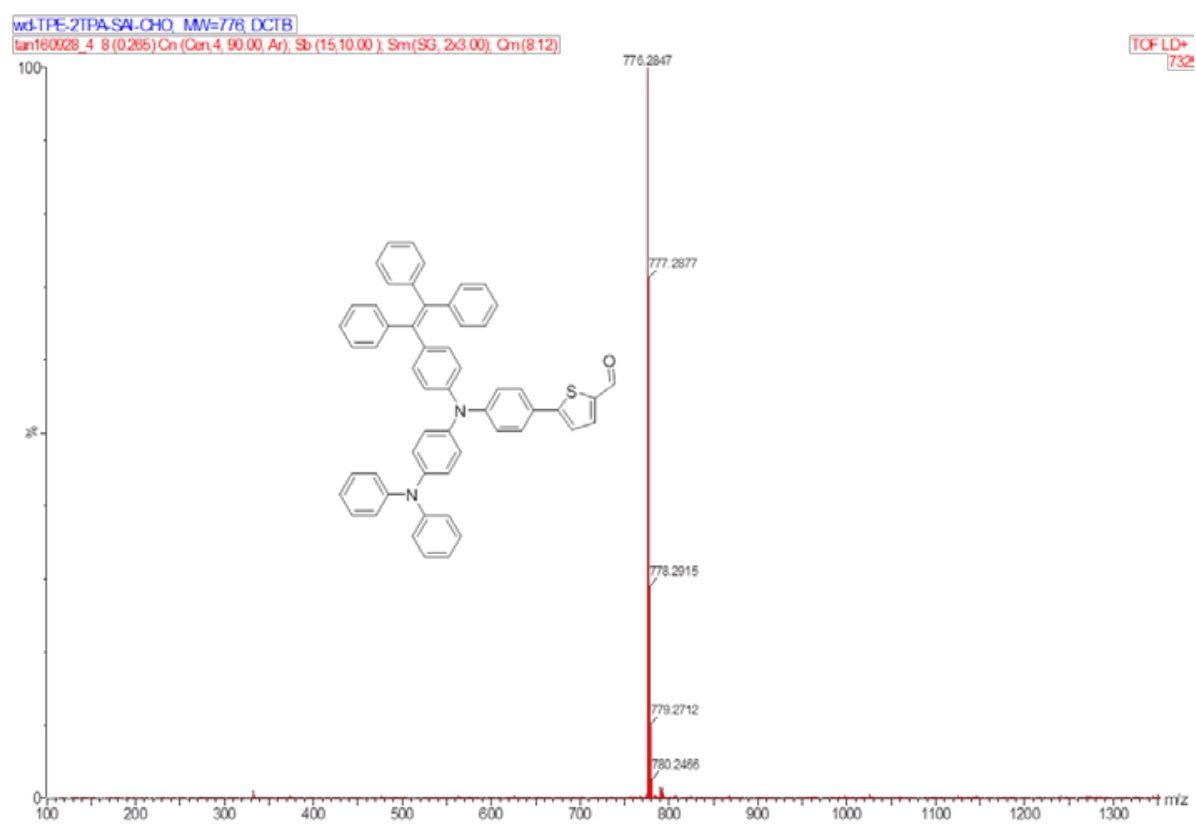

Figure S26. ESI HRMS spectrum of $\mathbf{4 c}$.

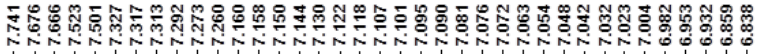

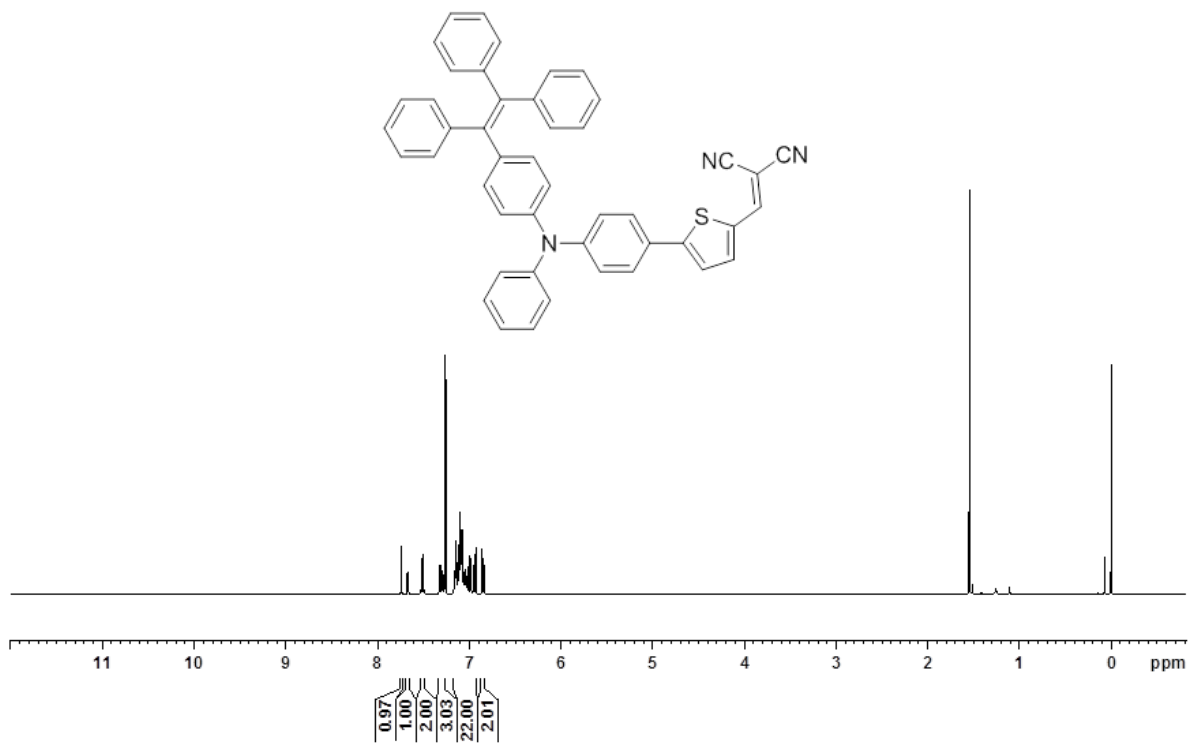

Figure S27. ${ }^{1} \mathrm{H}$ NMR spectrum of TPE-TTMN. 


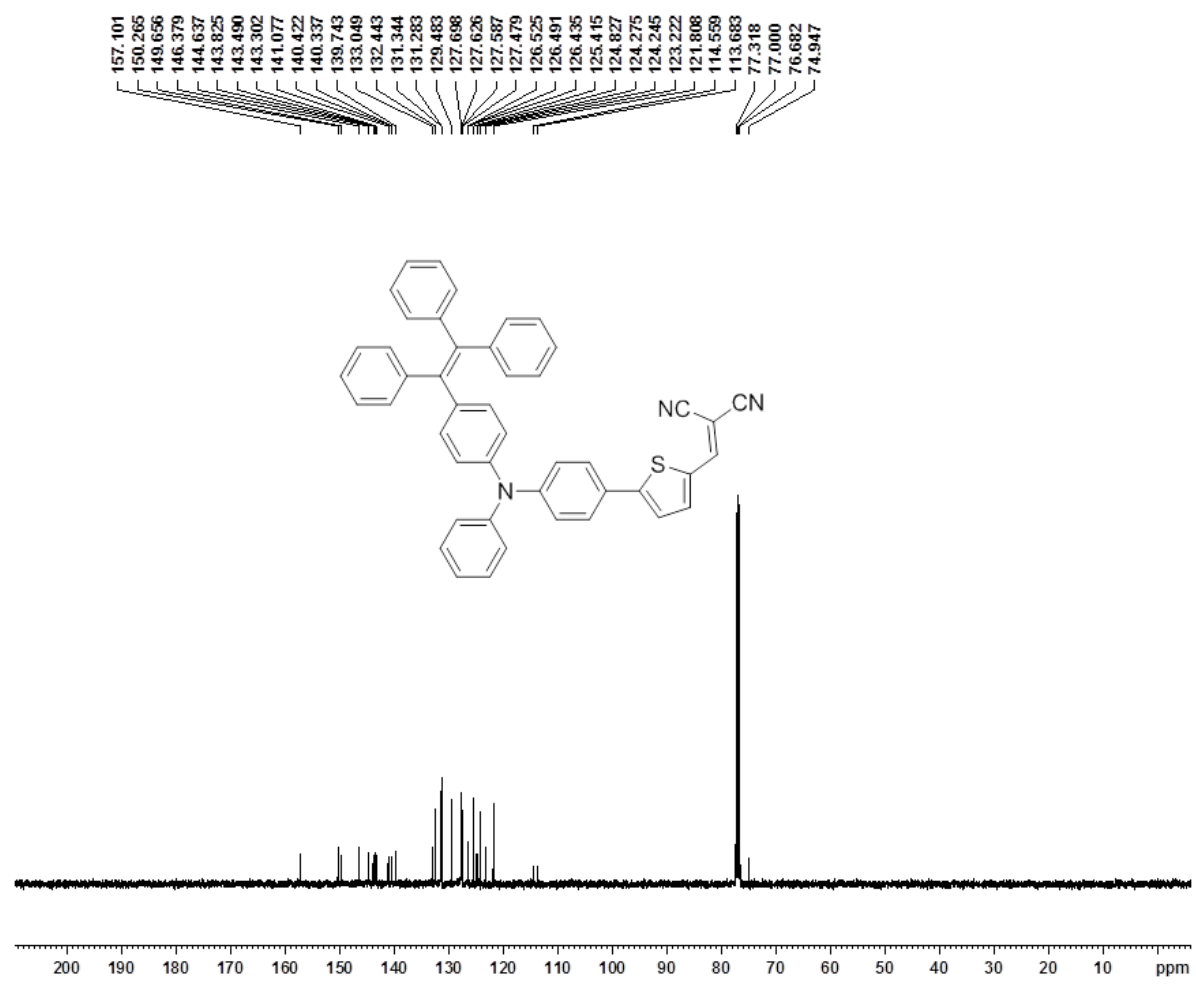

Figure S28. ${ }^{13} \mathrm{C}$ NMR spectrum of TPE-TTMN.

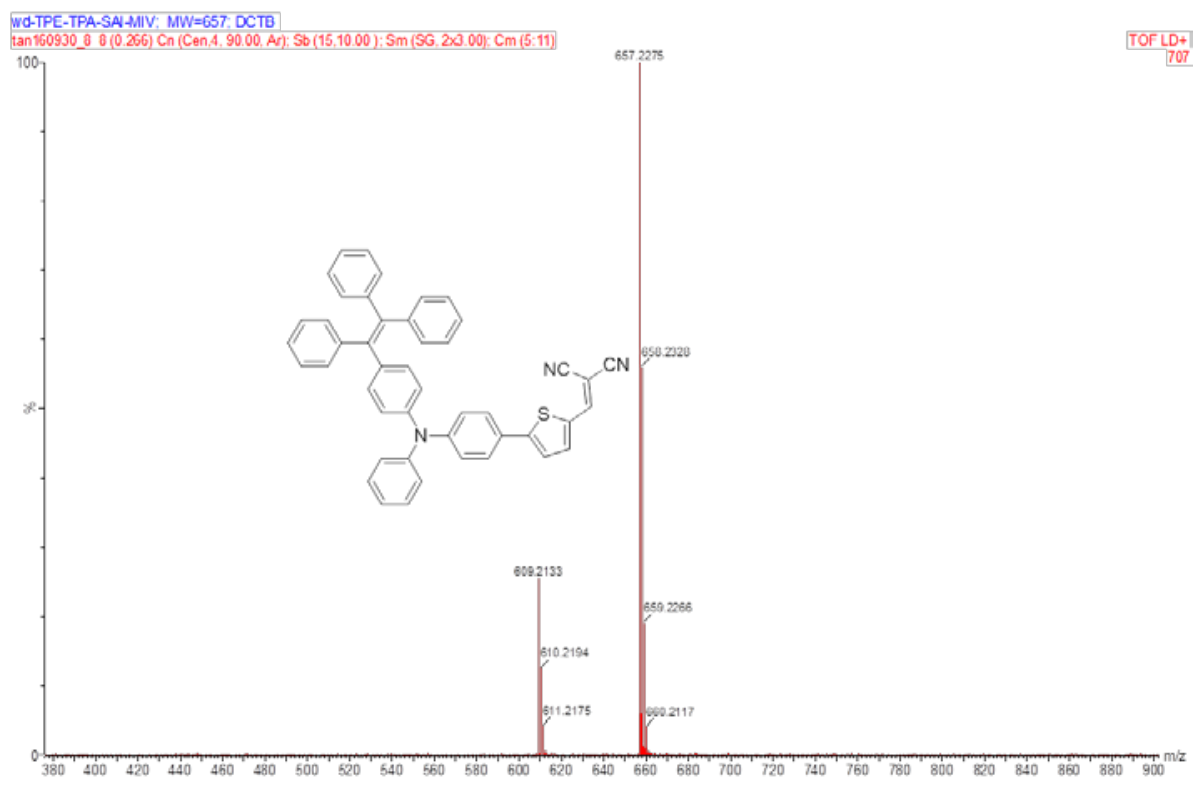

Figure S29. ESI HRMS spectrum of TPE-TTMN. 


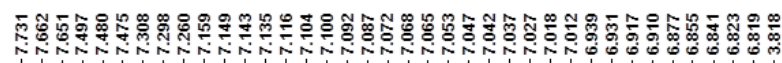
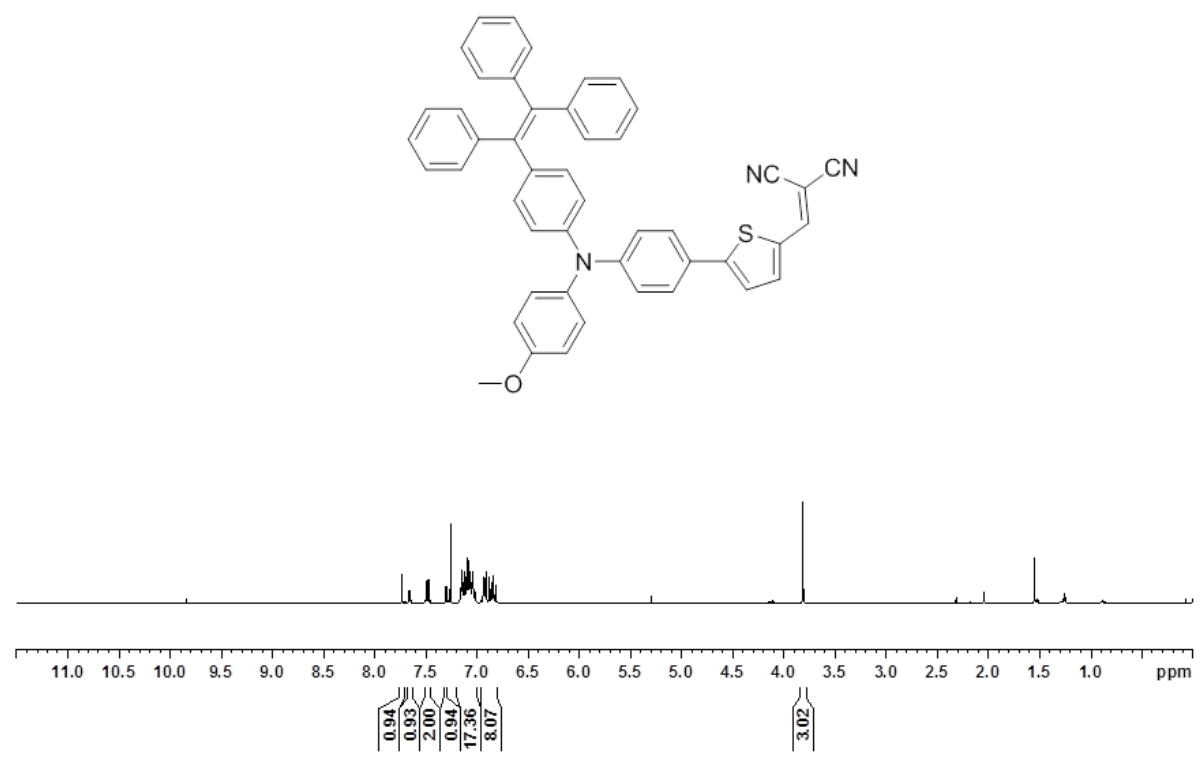

Figure S30. ${ }^{1} \mathrm{H}$ NMR spectrum of TPE-TTMN-OMe.
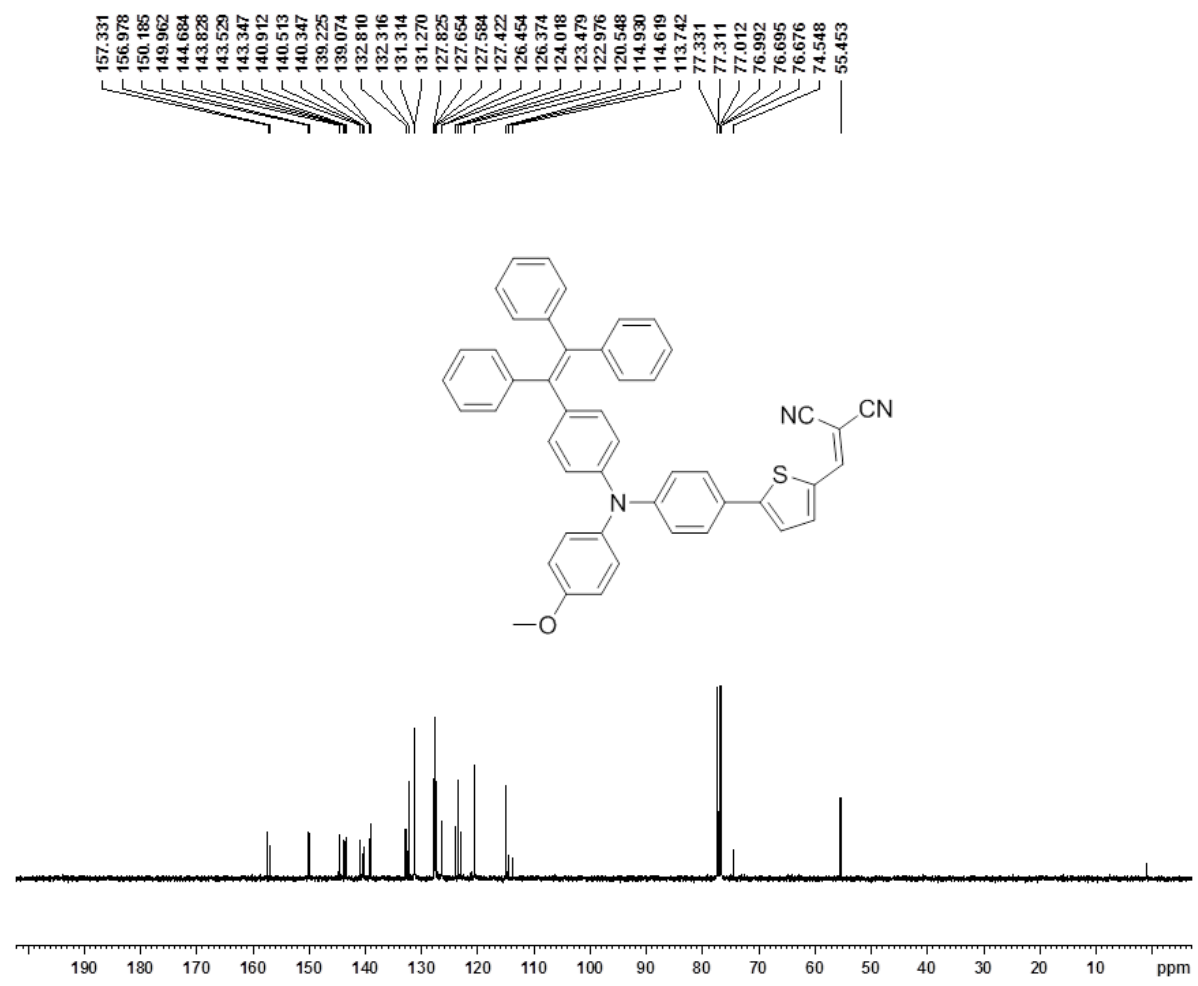

Figure S31. ${ }^{13} \mathrm{C}$ NMR spectrum of TPE-TTMN-OMe. 


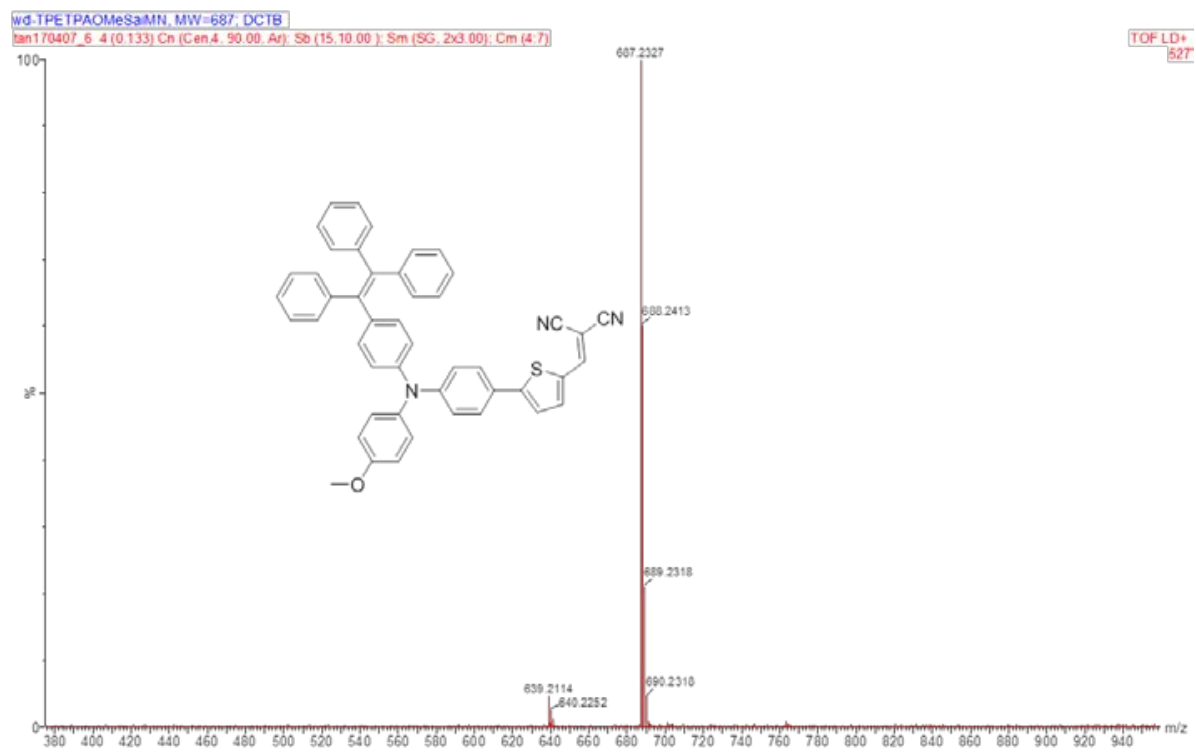

Figure S32. ESI HRMS spectrum of TPE-TTMN-OMe.

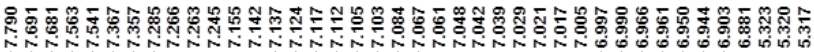

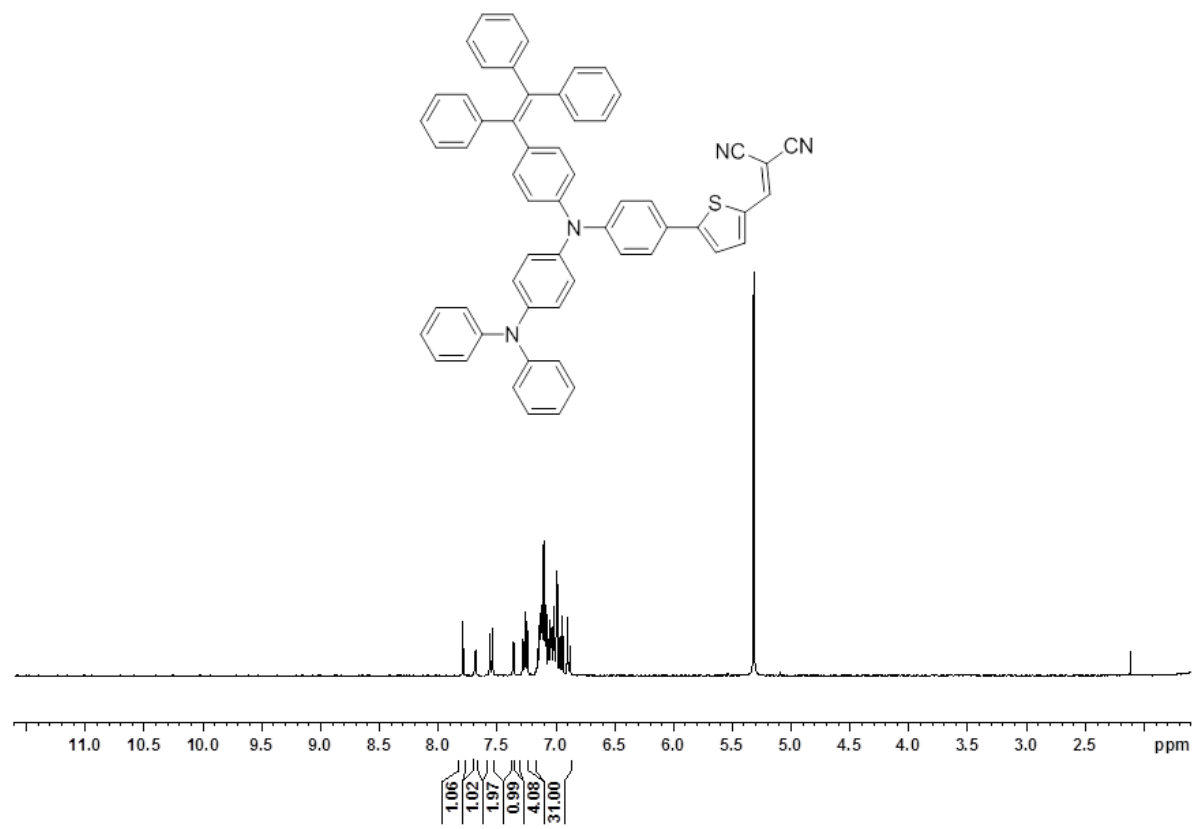

Figure S33. ${ }^{1} \mathrm{H}$ NMR spectrum of TPE-TTMN-TPA. 


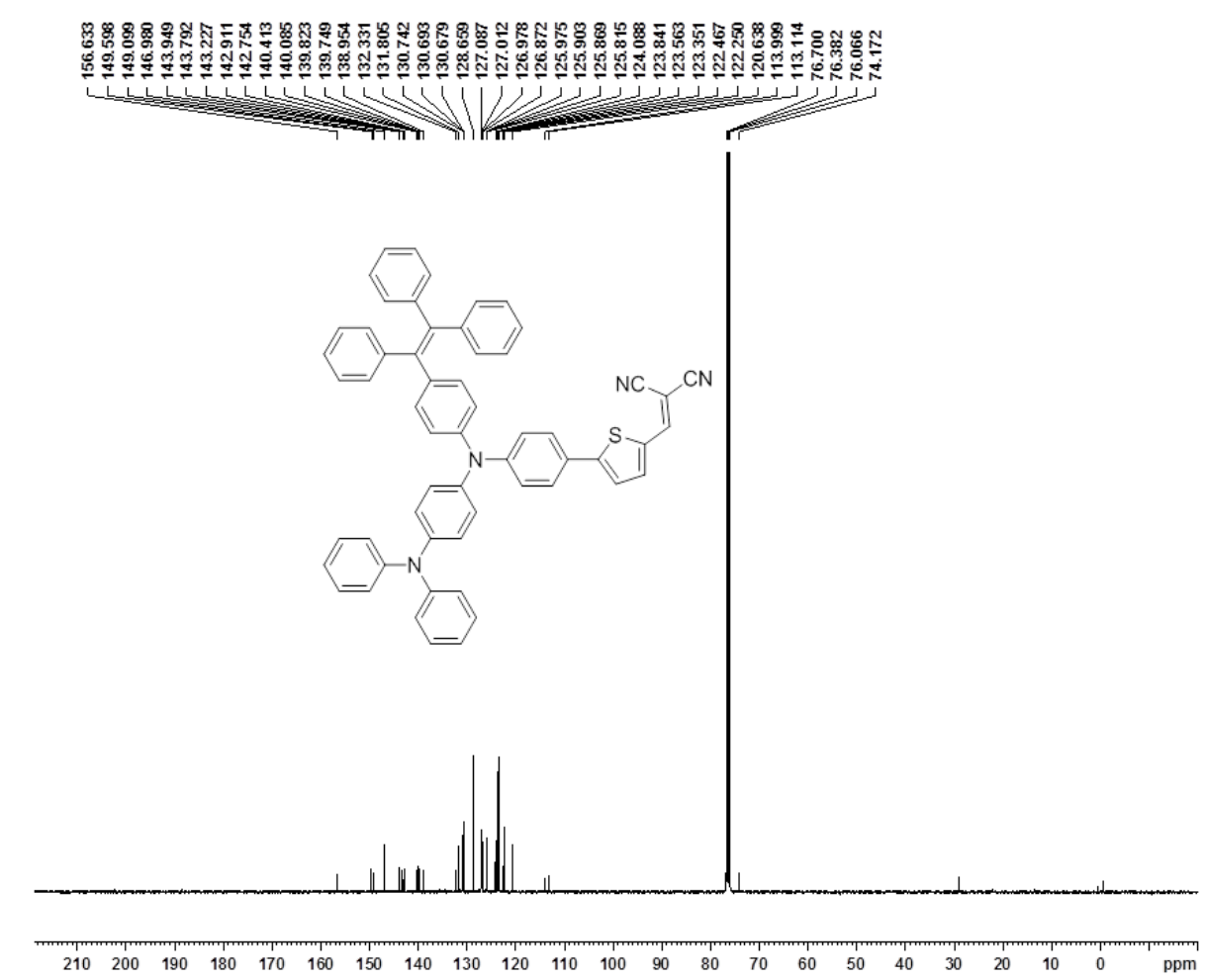

Figure S34. ${ }^{13} \mathrm{C}$ NMR spectrum of TPE-TTMN-TPA.

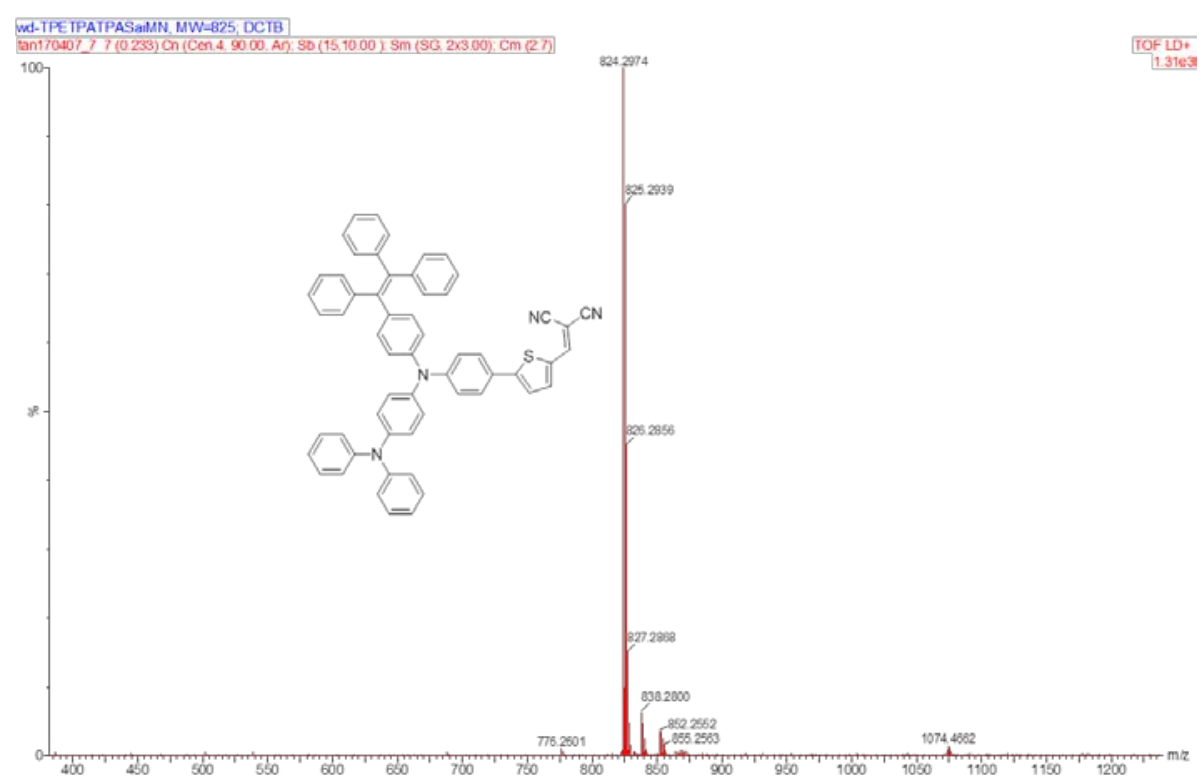

Figure S35. ESI HRMS spectrum of TPE-TTMN-TPA. 


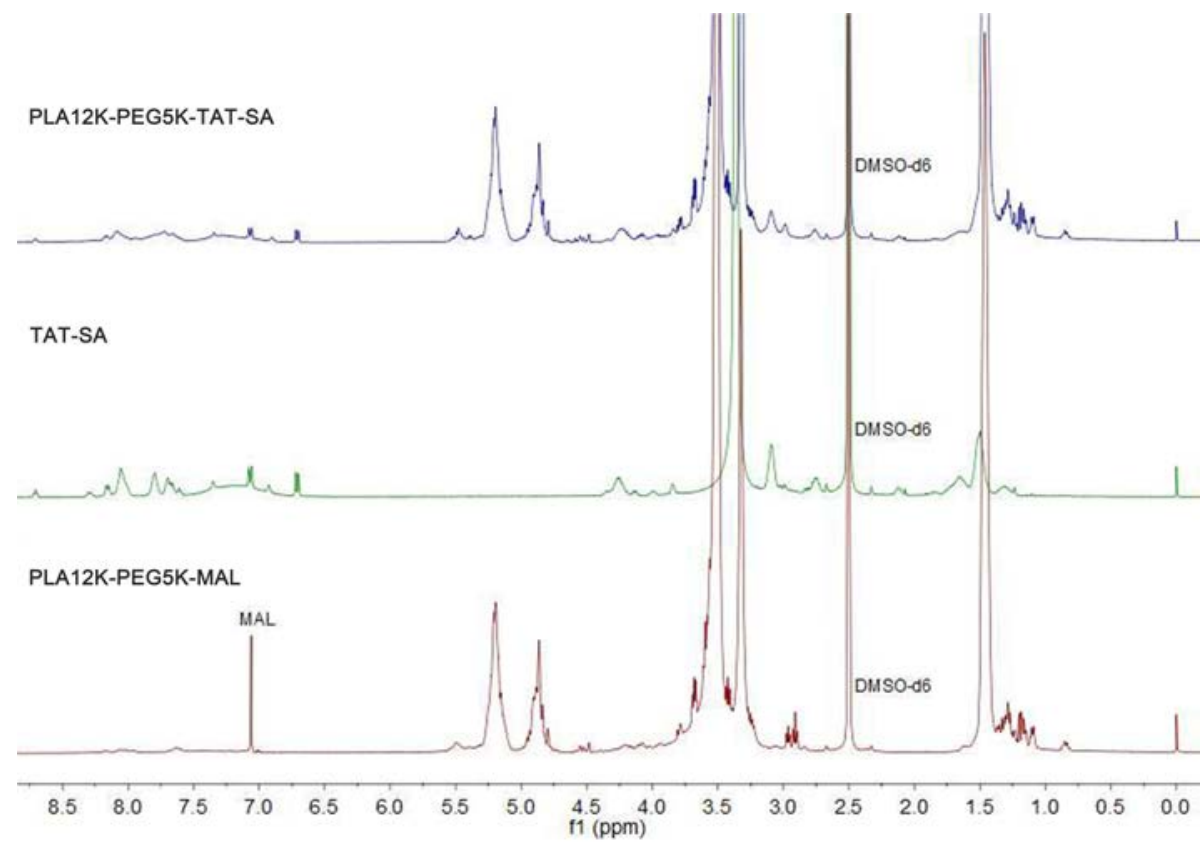

Figure S36. ${ }^{1} \mathrm{H}$ NMR spectra of PLA12K-PEG5K-TAT-SA and corresponding intermediates. 

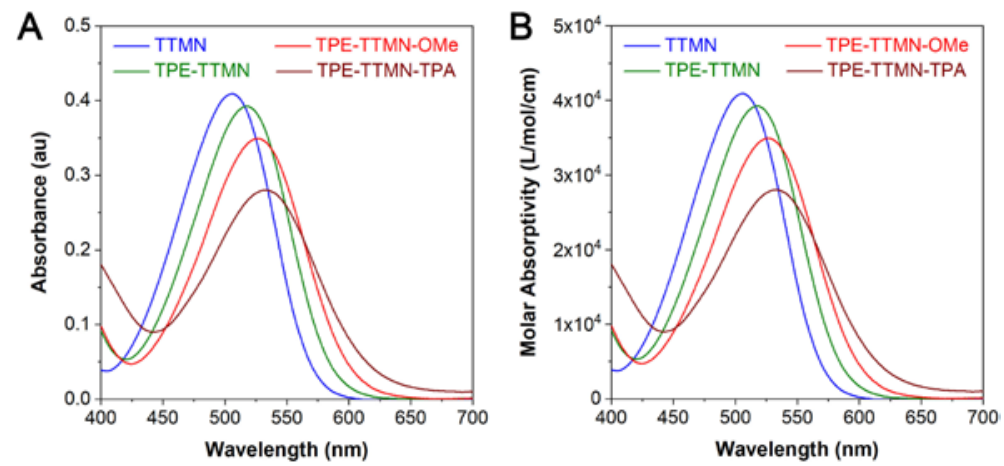

Figure S37. (A) The absorption spectra of these four AlEgens $(10 \mu \mathrm{M})$ and (B) the corresponding molar absorptivity in chloroform solution.

Table S1. Optical properties of those AIEgens.

\begin{tabular}{cccccccc}
\hline AIEgens & $\lambda_{\text {abs }^{\mathrm{a}}}$ & \multicolumn{3}{c}{$\lambda_{\mathrm{em}}(\mathrm{nm})$} & & $\alpha_{\mathrm{AII}}$ & $\tau^{\mathrm{e}}$ \\
\cline { 3 - 5 } & $(\mathrm{nm})$ & $\operatorname{Soln}\left(\Phi_{F}\right)^{\mathrm{b}, \mathrm{c}}$ & Aggr & Solid $\left(\Phi_{F}\right)^{\mathrm{c}, \mathrm{d}}$ & $\left(I_{\text {aggr, max }} / I_{\text {soln }}\right)$ & $(\mathrm{ns})$ \\
\hline TTMN & 506 & $662(0.32 \%)$ & 664 & $691(15.8 \%)$ & 12 & 7.42 \\
TPE-TTMN & 521 & $656(0.10 \%)$ & 670 & $694(26.2 \%)$ & 104 & 7.6 \\
TPE-TTMN-OMe & 534 & $667(0.23 \%)$ & 685 & $722(6.4 \%)$ & 129 & 6.47 \\
TPE-TTMN-TPA & 539 & $685(0.04 \%)$ & 712 & $770(1.4 \%)$ & 41 & 5.94
\end{tabular}

a Absorption maximum in chloroform solutions. ${ }^{b}$ Emission maximum in acetonitrile $(10 \mu \mathrm{M}){ }^{c}$ Fluorescence quantum yield determined by a calibrated integrating sphere. ${ }^{\mathrm{d}}$ Emission maximum in solid state. ${ }^{\text {e }}$ Fluorescence lifetime, measured under ambient conditions.
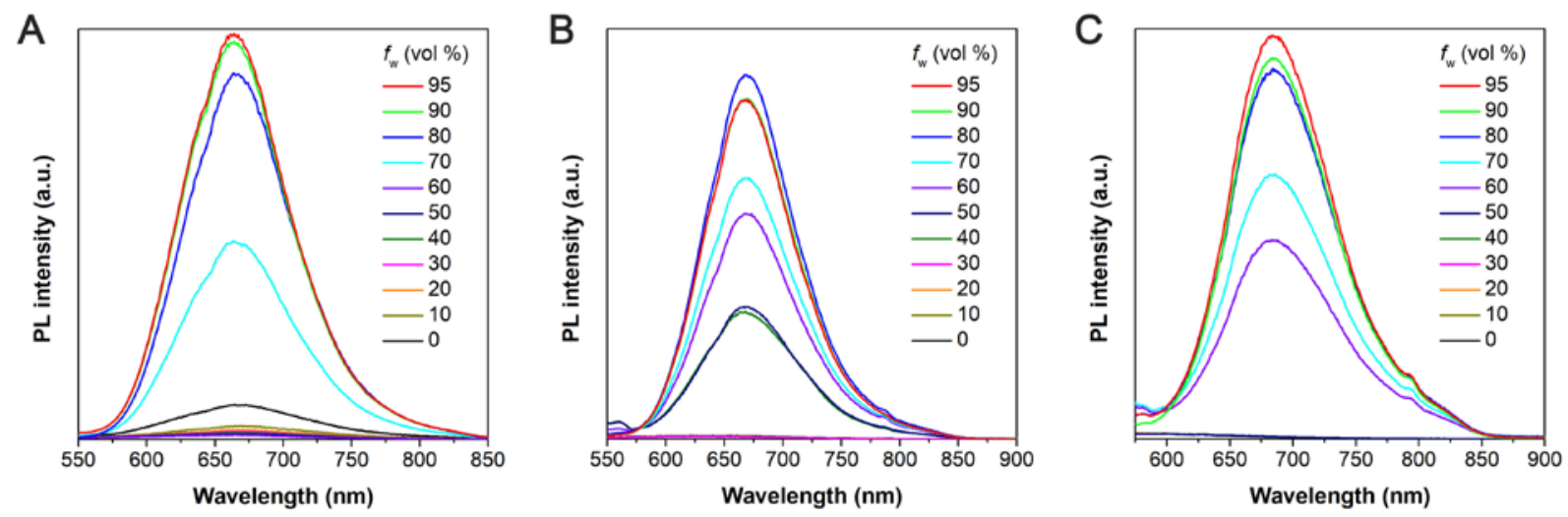

Figure S38. PL spectra of (A) TTMN, (B) TPE-TTMN and (C) TPE-TTMN-OMe in ACN/water mixtures with different water fractions $\left(f_{\mathrm{w}}\right)$; Concentration: $10 \mu \mathrm{M}$. 


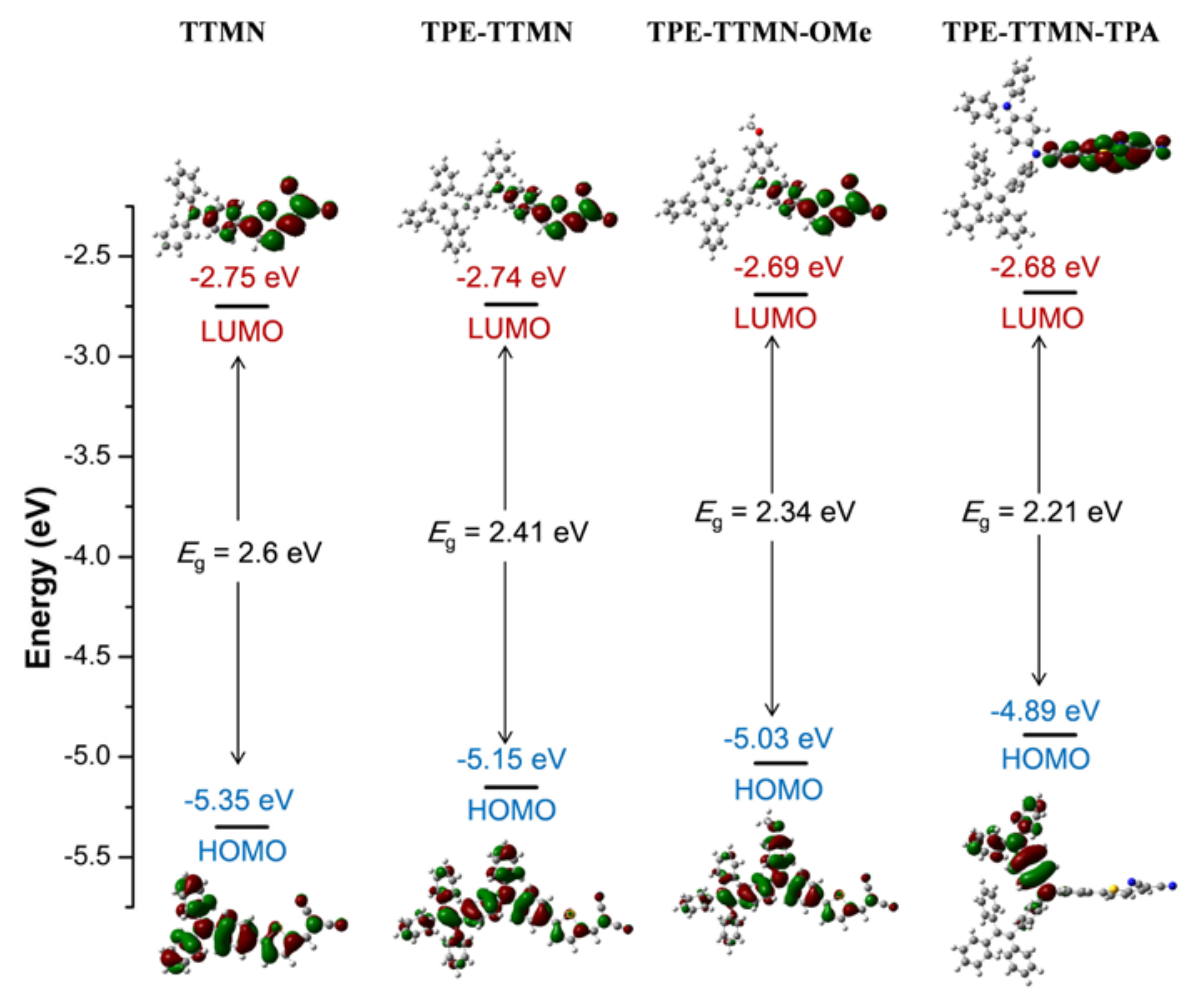

Figure S39. Calculated HOMOs and LUMOs of AIEgens.
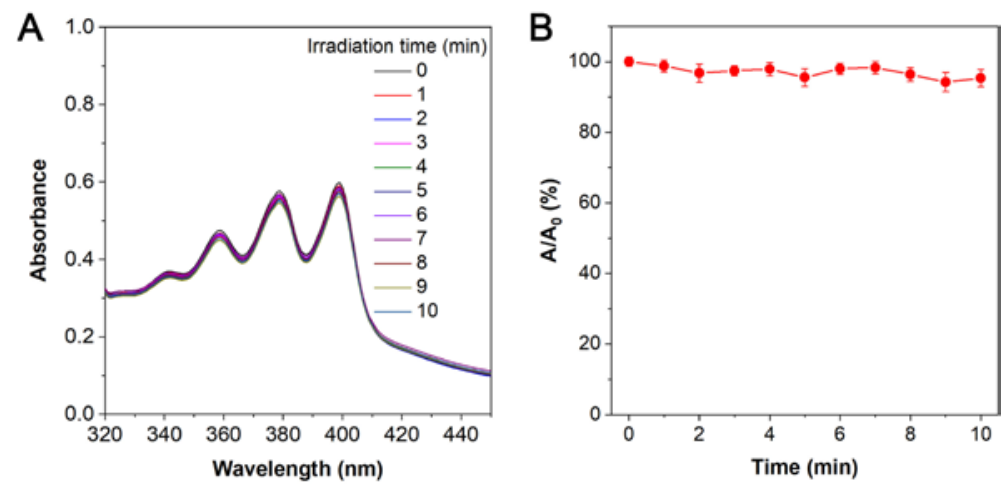

Figure S40. (A) Absorption of ABDA $(20 \mu \mathrm{M})$ in water in the presence of TPE-TTMN-TPA $(2 \mu \mathrm{M})$ under white light irradiation $\left(22.1 \mathrm{~mW} \mathrm{~cm}^{-2}\right)$ for different times. (B) Plots of the relative absorption intensity ( $\left.\mathrm{A} / \mathrm{A}_{0}\right)$ at $378 \mathrm{~nm}$ versus the irradiation time. 

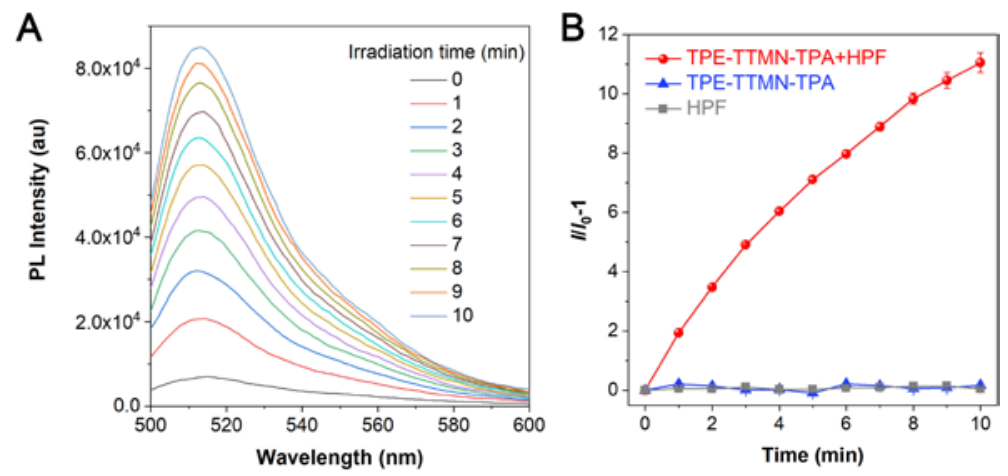

Figure S41. (A) PL spectra of mixtures of HPF $(0.5 \mu \mathrm{M})$ and TPE-TTMN-TPA $(0.2 \mu \mathrm{M})$ in PBS after white light irradiation (22.1 $\mathrm{mW} \mathrm{cm}^{-2}$ ) for different times. $\lambda$ ex: $490 \mathrm{~nm}$. (B) Plot of relative PL intensity $\left(I / I_{0}\right)$ at $515 \mathrm{~nm}$ versus the irradiation time.
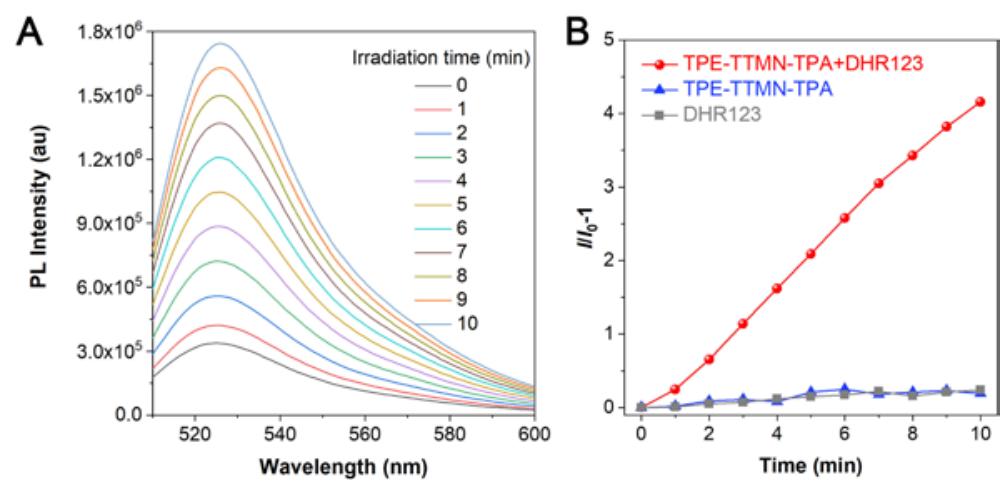

Figure S42. (A) PL spectra of mixtures of DHR123 $(0.5 \mu \mathrm{M})$ and TPE-TTMN-TPA $(0.2 \mu \mathrm{M})$ in PBS after white light irradiation (22.1 $\left.\mathrm{mW} \mathrm{cm}^{-2}\right)$ for different times. $\lambda$ ex: $495 \mathrm{~nm}$. (B) Plot of relative PL intensity $\left(I / I_{0}\right)$ at $526 \mathrm{~nm}$ versus the irradiation time.
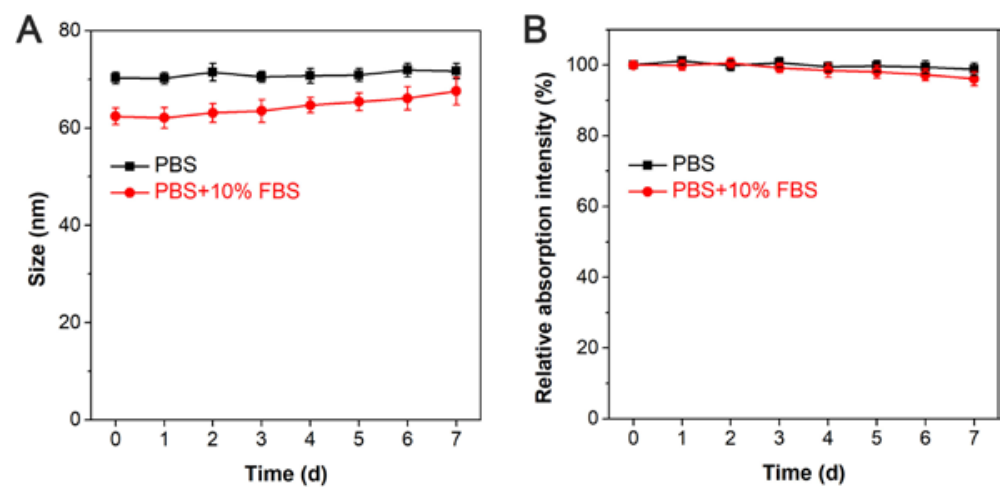

Figure S43. Stability analysis for (A) size variations and (B) absorption changes of T4-NPs with a concentration of $100 \mu \mathrm{g} \mathrm{mL}^{-1}$ as a function of storage time at room temperature in PBS or PBS $+10 \%$ FBS measured by DLS and UV-vis spectrometer (means $\pm S D, n=3$ ), respectively. 


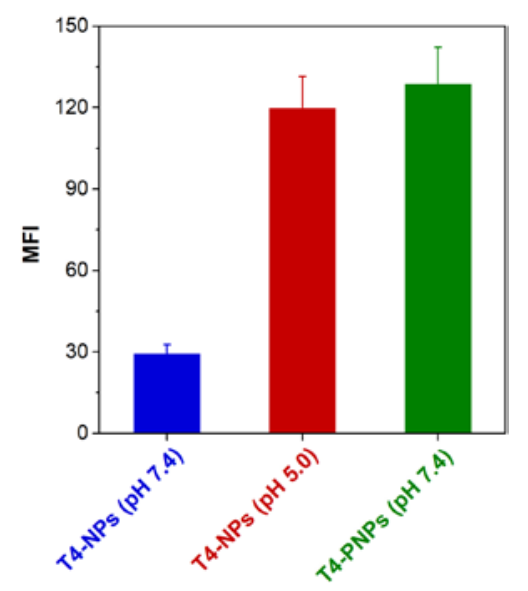

Figure S44. Quantitative mean fluorescence intensity (MFI) value of 4T1 cells after incubation with T4-NPs or T4-PNPs for $3 \mathrm{~h}$ at a unified T4 concentration of $5 \mu \mathrm{g} \mathrm{mL} \mathrm{m}^{-1}$ (mean $\pm \mathrm{SD}, \mathrm{n}=3$ ). These NPs were pretreated at $\mathrm{pH} 7.4$ or $5.0 \mathrm{PBS}$ for $24 \mathrm{~h}$ at $37^{\circ} \mathrm{C}$.
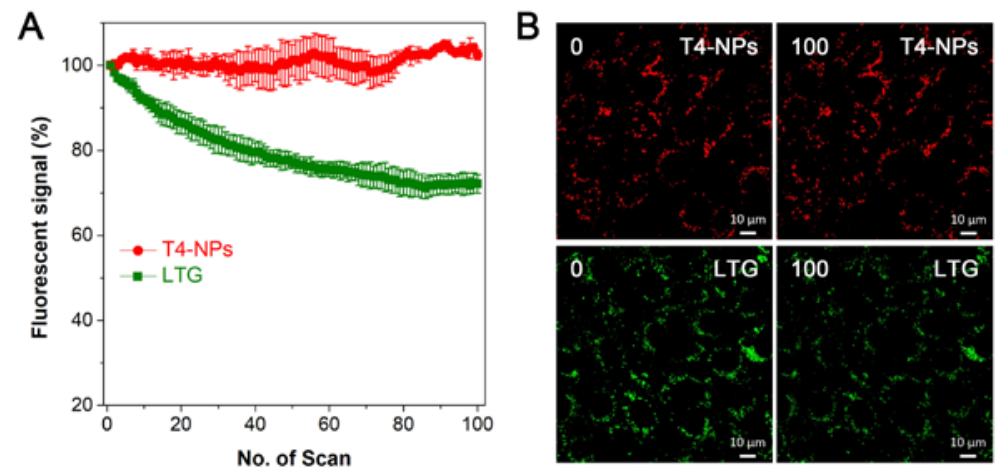

Figure S45. (A) The plot of the fluorescent signal loss of 4T1 cells co-stained with T4-NPs (5 $\mu \mathrm{g}$ $\left.\mathrm{mL}^{-1} \mathrm{~T} 4\right)$ and LTG $(100 \mu \mathrm{M})$ against the increasing laser irradiation scans by CLSM. Conditions: $\lambda$ ex: 543 nm (T4-NPs) and 488 nm (LTG); laser power: 2\% laser intensity. (B) CLSM images of 4T1 cells co-stained with T4-NPs (upper panel) and LTG (lower panel) before and after 10 laser irradiation scans. 


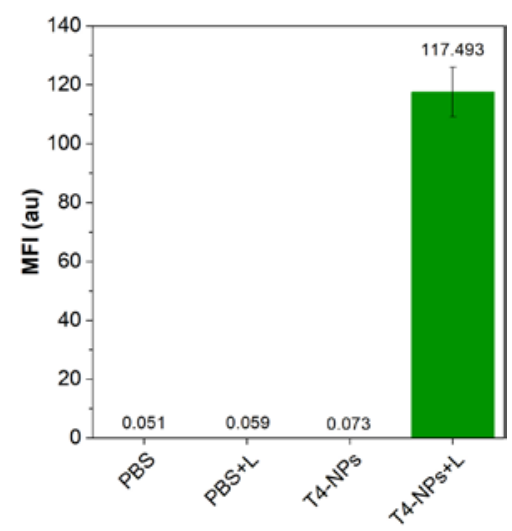

Figure S46. The quantitative mean fluorescence intensity (MFI) of DCFH inside cells with different treatments.

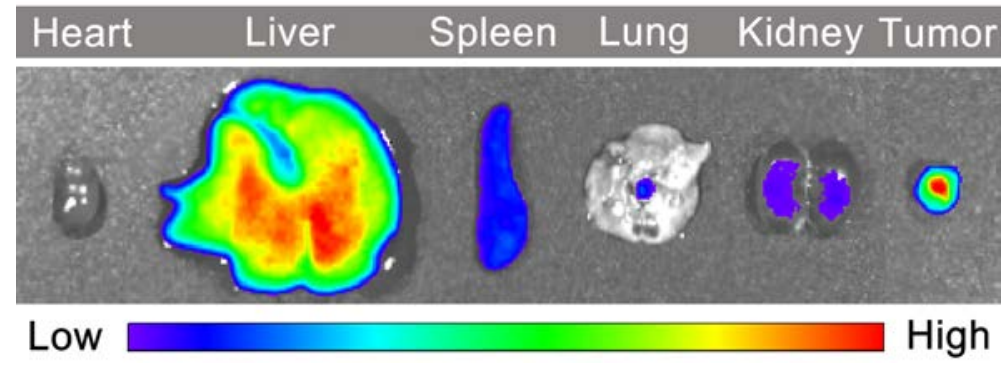

Figure S47. Ex vivo NIR fluorescent images of tumor and major organs after intravenous injection with T4-NPs (10 mg T4 $\left.\mathrm{kg}^{-1}\right)$ for $24 \mathrm{~h}$.

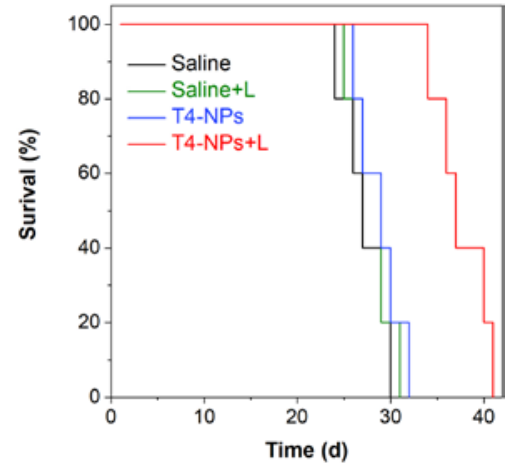

Figure S48. The survival curves of $4 \mathrm{~T} 1$ tumor-bearing BALB/c mice receiving different treatments. 
Table S2. Routine blood parameters of mice after different administrations.

\begin{tabular}{cccc}
\hline & Saline & T4-NPs & Reference range \\
\hline WBC $\left(10^{9} / \mathrm{L}\right)$ & $4.09 \pm 0.64$ & $4.38 \pm 0.74$ & $0.8 \sim 6.8$ \\
Lymph $\left(10^{9} / \mathrm{L}\right)$ & $3.05 \pm 0.73$ & $3.09 \pm 0.69$ & $0.7 \sim 5.7$ \\
Mon (\%) & $0.15 \pm 0.05$ & $0.17 \pm 0.06$ & $0.0 \sim 0.3$ \\
Gran (10\%/L) & $0.84 \pm 0.16$ & $0.88 \pm 0.18$ & $0.1 \sim 1.8$ \\
RBC (10 $/ \mathrm{L})$ & $8.49 \pm 1.18$ & $8.76 \pm 1.37$ & $6.36 \sim 9.42$ \\
HGB (g/l) & $134.6 \pm 6.32$ & $139.4 \pm 6.22$ & $110 \sim 143$ \\
HCT (\%) & $44.73 \pm 0.56$ & $44.66 \pm 0.68$ & $34.6 \sim 44.6$ \\
MCV (fl) & $48.38 \pm 0.73$ & $50.01 \pm 1.03$ & $48.2 \sim 58.3$ \\
MCH (pg) & $16.05 \pm 0.12$ & $16.86 \pm 0.22$ & $15.8 \sim 19$ \\
MCHC (g/l) & $332.4 \pm 10.3$ & $339.1 \pm 12.9$ & $302 \sim 353$ \\
RDW (\%) & $15.5 \pm 0.72$ & $16.05 \pm 0.61$ & $13 \sim 17$ \\
MPV (fl) & $5.51 \pm 0.14$ & $5.37 \pm 0.15$ & $3.8 \sim 6.0$ \\
\hline
\end{tabular}

\section{Reference:}

(1) Wang, D.; Su, H.; Kwok, R. T. K.; Shan, G.; Leung, A. C. S.; Lee, M. M. S.; Sung, H. H. Y.; Williams, I. D.; Lam, J. W. Y.; Tang, B. Z. Facile Synthesis of Red/NIR AIE Luminogens with Simple Structures, Bright Emissions, and High Photostabilities, and Their Applications for Specific Imaging of Lipid Droplets and Image-Guided Photodynamic Therapy. Adv. Funct. Mater. 2017, 27, 1704039. 